\title{
Recent Advanced Metabolic and Genetic Engineering of Phenylpropanoid Biosynthetic Pathways
}

\author{
Muhammad Anwar 1,2,+(D), Liu Chen ${ }^{1,2,+}$, Yibo Xiao ${ }^{1,2}$, Jinsong Wu ${ }^{3}$, Lihui Zeng ${ }^{4}$, Hui Li ${ }^{1}$, Qingyu Wu ${ }^{1,3}$ \\ and Zhangli $\mathrm{Hu}$ 1,3,*(D)
}

1 Guangdong Technology Research Center for Marine Algal Bioengineering, Guangdong Key Laboratory of Plant Epigenetics, College of Life Sciences and Oceanography, Shenzhen University, Shenzhen 518060, China; postdoc@szu.edu.cn (M.A.); liuchenneo@163.com (L.C.); yiboxiao@szu.edu.cn (Y.X.); lihui80@szu.edu.cn (H.L.); qingyu@tsinghua.edu.cn (Q.W.)

2 Key Laboratory of Optoelectronic Devices and Systems of Ministry of Education and Guangdong Province, College of Optoelectronic Engineering, Shenzhen University, Shenzhen 518060, China

3 Shenzhen Key Laboratory of Marine Bioresource \& Eco-Environmental Science, Longhua Innovation Institute for Biotechnology, Shenzhen University, Shenzhen 518060, China; 1800252001@email.szu.edu.cn

4 College of Horticulture, Fujian Agriculture and Forestry University, Fuzhou 350002, China; lhzeng@fafu.edu.cn

* Correspondence: huzl@szu.edu.cn

+ These authors contributed equally to this work.

Citation: Anwar, M.; Chen, L.; Xiao, Y.; Wu, J.; Zeng, L.; Li, H.; Wu, Q.; Hu, Z. Recent Advanced Metabolic and Genetic Engineering of Phenylpropanoid Biosynthetic Pathways. Int. J. Mol. Sci. 2021, 22, 9544. https://doi.org/10.3390/ ijms22179544

Academic Editor: Ryszard Lobinski

Received: 29 July 2021

Accepted: 25 August 2021

Published: 3 September 2021

Publisher's Note: MDPI stays neutral with regard to jurisdictional claims in published maps and institutional affiliations.

Copyright: (c) 2021 by the authors. Licensee MDPI, Basel, Switzerland. This article is an open access article distributed under the terms and conditions of the Creative Commons Attribution (CC BY) license (https:// creativecommons.org/licenses/by/ $4.0 /)$.

\begin{abstract}
The MYB transcription factors (TFs) are evolving as critical role in the regulation of the phenylpropanoid and tanshinones biosynthetic pathway. MYB TFs relate to a very important gene family, which are involved in the regulation of primary and secondary metabolisms, terpenoids, bioactive compounds, plant defense against various stresses and cell morphology. R2R3 MYB TFs contained a conserved N-terminal domain, but the domain at C-terminal sorts them different regarding their structures and functions. MYB TFs suppressors generally possess particular repressive motifs, such as pdLNLD/ELxiG/S and TLLLFR, which contribute to their suppression role through a diversity of complex regulatory mechanisms. A novel flower specific "NF/YWSV/MEDF/LW" conserved motif has a great potential to understand the mechanisms of flower development. In the current review, we summarize recent advanced progress of MYB TFs on transcription regulation, posttranscriptional, microRNA, conserved motif and propose directions to future prospective research. We further suggest there should be more focus on the investigation for the role of MYB TFs in microalgae, which has great potential for heterologous protein expression system for future perspectives.
\end{abstract}

Keywords: tanshinones; phenolic acid; plant defense; pdLNLD/ELxiG/S motif; flavonoids; repressor MYB; bioactive compounds

\section{Introduction}

The compounds derived from phenylpropanoid denote a different class of secondary metabolites, which start from key enzyme phenylalanine. Phenylpropanoid derived metabolites play an important function in plant resistance mechanisms against biotic and abiotic stress, regulate plant growth and development [1,2] and male fertility [3]. Several of these phenylpropanoid derived compounds are considered to be valuable to human welfare and health. MYB protein associated with a big class of transcription factors, which are responsible for the regulation of the biosynthetic pathway of phenylpropanoid resulting compounds [4]. In plants, phenylpropanoid derived secondary metabolites mainly consist of flavonoid, monolignol, stilbenes, terpenoids and different phenolic acid. Many of these compounds play a key role in identified plants, including as UV light protectants, phytoalexins, carotenoids, strengthen the cell wall and signaling molecules [5].

The pigments that provide the different colors to vegetables, fruits, ornamental foliage, leaves, ornamental flowers and seeds are called flavonoids, which provide health benefits 
to the human and animals [6]. Flavonoids are the secondary metabolites that are broadly distributed in the plant kingdom, which play key roles in plant defense and development. These secondary metabolites can be divided into different groups based on differences in their structure, such as anthocyanin, proanthocyanin, chalcones, flavones, flavonols, flavandiols, isoflavonoids and phlobaphenes [7]. Flavonoids are the most common occurring pigment in plants. Anthocyanins are commonly known as flavonoid compounds providing blues, pink hues, orange, yellow and red colors to flowers, fruits and vegetables. Anthocyanins play very significant physiological and ecological roles in plants. Anthocyanin is most noticeable in young leaves where they defend developing tissues from light stress. Anthocyanins play a key role in seed dispersal and pollination by attracting the pollinator agent in mature fruits and flowers. Proanthocyanin (also known as tannins) provides as significantly roles, such as strengthening the seed coat and stress tolerance in plants [8]. Furthermore, these compounds are concerned in the regulation signaling, when legume are in nodulation process, transportation of auxin and male fertility determination. Moreover, these compounds are involved in plant defense in opposition to stress (biotic and abiotic). These compounds have very imperative values as nutritional and pharmaceutical compounds [9].

Phenylalanine ammonia-lyase $(P A L)$, cinnamate 4-hydroxylase $(C 4 H)$, and p-coumaroyl coenzyme A ligase (4CL) are very important key enzymes, which jointly catalyzed stages (First three stages) involved in biosynthesis of compounds, which are derived from phenylpropanoid, as shown in (Figure 1).

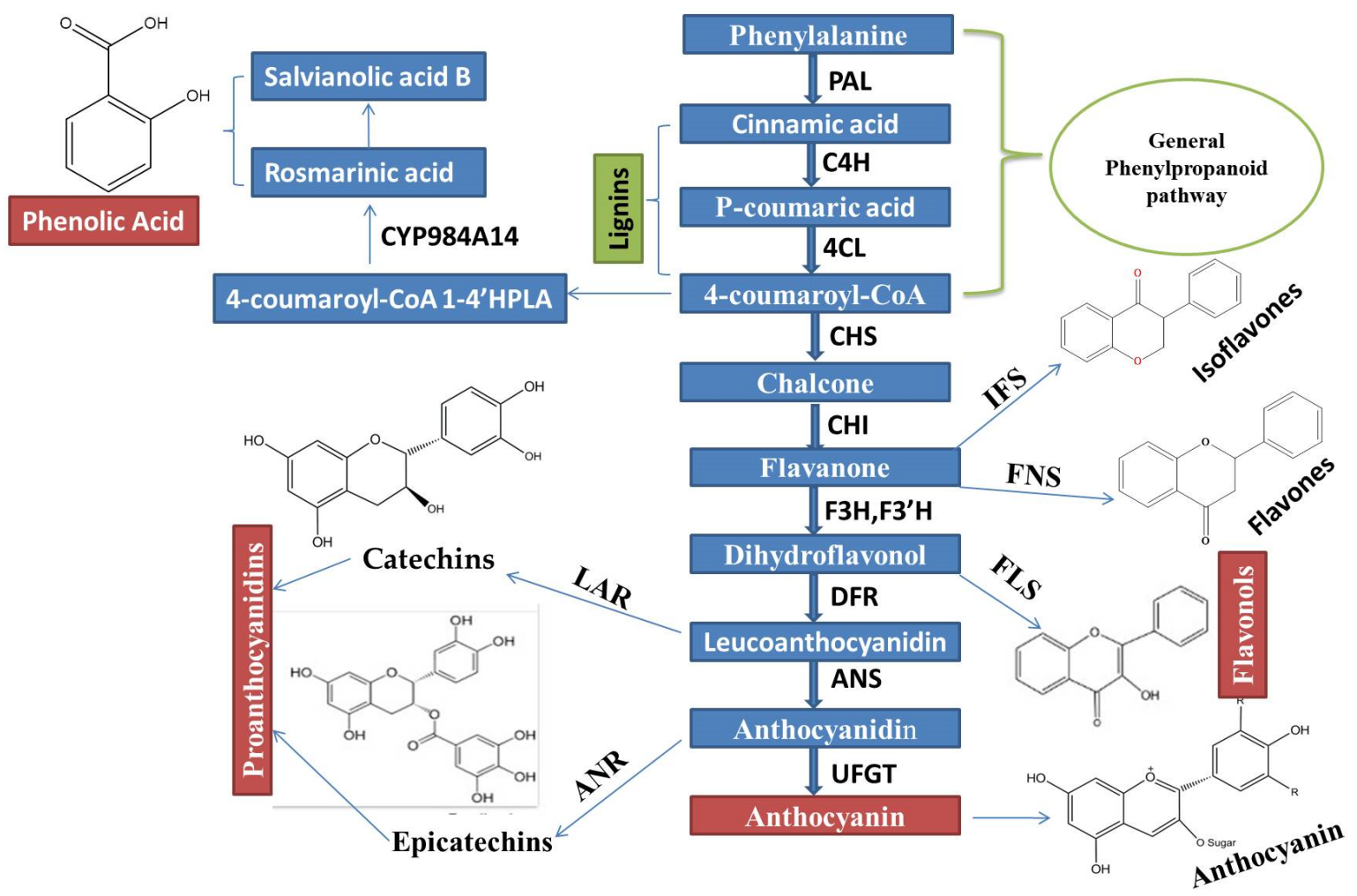

Figure 1. An Integrated regulatory mechanisms network of the Phenylpropanoid biosynthetic pathway, which is controlled through MYB TFs and MBW complex activation, is constructed based on the recent remarkable research advancement.

Various transcription factors (TFs), including R2R3 MYB, WD40 repeat (WDR) proteins and basic helix-loop-helix ( $b H L H)$ and control the biosynthesis of flavonoid compounds [10]. A complex of MYB-bHLH-WDR (MBW) shows action, in order to trigger the structural genes responsible for the process of flavonoid biosynthesis. In several plants, including Helianthus annuus L., Arabodopsis thialana, Mimulus guttatus, Camellia sinensis, Narcissus 
tazetta. L. Narcissus tazetta, Zea mays, Glycine max, Medicago truncatula, Fragaria $\times$ ananassa, populous, Petunia $x$ hybrida, Malus domestica, and Vitis vinifera L., these transcription factors have been functionally characterized well [11-19]. This analysis encapsulates the recent understanding of MYB proteins and their function in controlling phenylpropanoid metabolisms in plants, as well as further studies to understand the complexity of their network of regulatory mechanisms.

\section{Mechanisms of MYB Gene Family as a Transcription Factor}

Cellular processes are regulated by transcription factors (TFs), which can modify complex or intricate traits in plants and could play a prominent part in next-generation biotechnology. There are limitations in genomic diversity in traditional breeding. However, transgenic methodologies surpass genetic obstacles by improving the regulatory pathways of one crop by integrating TFs of other crop or plant species [20]. Genes that encode TFs containing DNA binding motifs, e.g., MYB, ERF/AP2, Zinc fingers and bZIP are signalinduced. These TFs further regulate many functional genes during different conditions of stress or morphogenesis. Therefore, identifying novel TF genes responsible for regulating particular gene expression will improve our understating of signaling pathways related to the development and growth of innovative transgenic crops. MYB is a functionally diverse and large protein family present in all eukaryotic organisms [21]. Many MYB acts as TFs having a different number of MYB domains that are able to bind DNA. They interact with other TFs and are also involved in ABA response, which represents their wide distribution among plants. Detailed functional characterization of these proteins in Arabidopsis thaliana depicts their variety of roles in plant-specific mechanisms. The cell cycle of eukaryotes is controlled by 'classical' MYB factors that are linked with c-Myb. First, MYB gene identification was form avian virus myeloblastosis, which was 'oncogene' v-MYB [22].

\section{Evolution of MYB Transcription Factors}

The protein of MYB family contains DNA binding domain. There are two particular conserved regions present in MYB protein, C-terminal of R2R3 MYB protein, which show structural and functional diversity in their amino acid sequence, which are responsible for various regulation activities in plants. While, N-terminal show binding domain of MYB DNA are conserved. Generally, the domain of MYB protein comprises sequences with four imperfect amino acid repeats of approximately 52 amino acids, each establishing three $\alpha-$ helices. Ogata, et al. [23] described that Helix-turn-helix structure, which are built through each repeat of second and third helices with regularly spaced three tryptophan residues, resulting in hydrophobic central in HTH structure (3D). Interestingly, first tryptophan in R3 domain is replaced with isoleucine or phenylalanine in plants. MYB family could be separated into four group based on MYB domain number [2,24]. In plants (monocots and dicots), plentiful kind of R2R3-MYB TFs are specific [25]. The plant taxon represents the highest diversity, with the presence of all four classes of MYB proteins. The group of 4R-MYB indicates the smallest class and its members have four R1/R2-type repeats. Several plant genomes contain single 4R-MYB encoded protein. However, the second class retains 3R-MYB protein of R1R2R3 type, which is composed of higher plant genomes, is particularly encoded by five genes. R2R3-MYB domain is more conserved as compared to its other region, which shows more divergence. The division of R2R3-MYB proteins into subgroups is based on amino acid motifs, which are present at $C$ terminal [2].

MYB domain sequence-based evolutionary studies from various organisms represent that plant ancestor initially had three repeats and out of which the first repeat was lost during the course of time. Lipsick [21] has described an evolutionary model of MYB proteins. This model reveals that R1R2R3-MYBs resulted due to consecutive intragenic duplications and triplications among the primeval eukaryotes, and they produced two repeat and three repeat (R1R2R3-MYB, R2R3-MYB) proteins in animals and plants, respectively. During plant evolution through selective subgroup expansion and amplification, 
numerous subgroups genes harboring R2R3MYB proteins were made due to the loss of R1 [26]. The consecutive gain of repeat units generated MYB genes. The detailed study of MYB genes regarding their classification, structure, characteristics, mechanism of combinational control, multi-functionality, functional redundancy and gain model for evolution have been reviewed comprehensively by Du, et al. [27] and Dubos, Stracke, Grotewold, Weisshaar, Martin and Lepiniec [24]. It is very interesting that the heterogeneous class consists of proteins with partial or single MYB repeat, jointly known as "MYB-related", which is further divided into many subclasses [28]. The loss of sequence regarding R1 repeat and successive extension of gene family resulted in R2R3-MYB class after evolution from R1R2-MYB gene predecessor [28].

Moreover, it has also been proposed that ancient intragenic duplication by gaining the sequence encoding R1 repeat from R2R3-MYB genes resulted in the evolution of 3RMYB [29]. Arabidopsis AtMYB48 and AtMYB59 and their rice homologs (OsMYBAS2 and OsMYBAS1), the two R2R3-MYB genes experience alternative splicing in the same way and result in three diverse merged transcripts in rice, and four in Arabidopsis. Therefore, a deep-rooted understanding of another splicing of MYB protein will further enlighten us regarding gene evolution in dicots and monocots, as well as development-related regulation by transcription factor genes [29].

\section{Recent Transcriptomic and Genome-Wide Analysis and Expression of MYB Transcription Factors}

In sugarcane, 202 MYB TFs are explored, some of them are expressed mainly in stem and are actively responded to drought stress resistance and mosaic diseases [30]. In Arabidopsis 198 MYBs have been identified; among them, 126 are encoded for R2R3MYB proteins [31]. Recently, 223 MYB (112 R2R3-MYB, 2 R1R2R3-MYB and 119 R1MYB) transcription factors were recognized in the potato genome [32]. Recently, there are 69 GbMYB transcription factors are identified in Ginkgo biloba, out of which 19 R2R3 MYB are responsive to hormonal and abiotic stresses [33]. In maize, a genome-wide survey indicated that they consist of 157 R2R3-MYB proteins [34]. R2R3-MYB (185) transcription factors are reported in the genome of Mangrove, 34 MYB gene are mainly expressed in different tissues (root, leaves), which are related to various stresses (salinity and drought) [35]. Hippophae rhamnoides is the rich source of secondary metabolites, which has economic importance regarding medicinal and nutritional values, 161 R2R3-MYB TFs were obtained through its genome-wide analysis [36]. In a recent study, 111 StR2R3-MYB transcription factors are reported in potato [37]. In the genome of flax, 167 R2R3-MYB, 7 R3-MYB, and 1R4MYB transcription factors have been identified [38]. However, in soybean, 252 total MYBs were identified and account for about $4 \%$ of all transcription factors. They consist of two (4R-MYB) genes, six (3R-MYB) proteins and 244 encodings for R2R3-MYB proteins [39]. Genome-wide analysis of apples revealed that they contained 229 MYB transcription factors. Another recent study has explored 251 and 305 MYB TFs from Musa balbisiana and Musa acuminata, respectively by [40].

\section{Biological Functions Regulated through MYB Transcription Factors}

MYB TFs control many plant-specific processes. By using molecular and genetic analysis the function of MYB proteins have been greatly described among various plant species, like petunia (Petunia hybrida), apple (Malus domestica), poplar (Populus tremuloides), snapdragon (Antirrhinum majus), grapevine (Vitis vinifera L.), maize (Zea mays) and Arabidopsis thaliana [41]. R2R3-MYB TFs have been widely investigated during last decade and their involvement in several processes have been revealed, such as abiotic and biotic stress [42,43], cold tolerance [41], phenylpropanoid metabolism [44,45], trichomes development [46], flower shape [47], cell shape [48], plant defense mechanisms [49-52], cell wall development [53] and stomatal closure [54]. 


\section{MYB Transcription Factors and Plant Defense Mechanisms}

The growth and development of plants are strongly affected by different stresses, including extreme temperature, drought, salinity and cold stress. Several transcriptions factors facilitate stress responses in plants, such as NAC, WRKY, bZIP and MYB. MYB family among them is considered the largest families of transcription factors. MYB protein link to various cis-acting motifs, such as MBSI (T/C)AAC $(\mathrm{G} / \mathrm{T}) \mathrm{G}(\mathrm{A} / \mathrm{C} / \mathrm{T})(\mathrm{A} / \mathrm{C} / \mathrm{T})$, MBSII $(\mathrm{A} / \mathrm{G})(\mathrm{G} / \mathrm{T}) \mathrm{T}(\mathrm{A} / \mathrm{T}) \mathrm{GGT}(\mathrm{A} / \mathrm{G}), \mathrm{MBSIIG} \mathrm{ACC}(\mathrm{A} / \mathrm{T}) \mathrm{ACC}(\mathrm{A} / \mathrm{C} / \mathrm{T})$, which are associated to resistance to low temperature and cell cycle control, secondary cell wall biosynthesis and flavonoid biosynthesis respectively. MYBCORE, CTGTTG, CAGTTA, which are involved in drought tolerance. MYBs in plants regulate abiotic responses, for example, BplMYB46, improve osmatic and salt tolerance in Betula platyphylla by influencing the $S O D$ and $P O D$ genes, to improve both proline levels and reactive oxygen species scavenging, and reduced water loss by regulating stomatal aperture [55]. GhMYB4, transcription factors induce resistance against verticillium dahlia in cotton. It provide a great potential for the improvement in breeding of cotton plants [56]. High temperature induces the MYB transcriptional factor and positive regulator of thermotolerance [54]. MdMYB308L positively regulate anthocyanin accumulation and cold tolerance in apple by interacting with MdbHLH33 [41]. StMYB030, which is the homology of AtMYB44, increased the salt stress tolerance in transgenic plants of Arabidopsis upon its overexpression [32]. VdMYB1 from Chinese wild grape stimulates defense response against pathogen attack [52]. GhMYB108-like plays a key regulating role in response to salt and drought stresses [57,58]. The over-expression of GmMYB81 in Arabidopsis thaliana increases the rates of seed germination under drought and salts stress [59]. EaMYB18, was isolated from sugarcane, encoding a single R3 repeat MYB DNA binding domain, showed the highest potential for cold and drought stress tolerance [58]. The overexpression of OsMYB-R1 in transgenic rice increased tolerance under $C r(V 1)$ and drought exposure [60]. OsMYB30 regulates the expression of OsPAL6 and OsPAL, which play an important role in providing resistance in rice against brown planthopper [61] (see Table 1).

Table 1. MYB TFs involved in plant defense mechanisms.

\begin{tabular}{|c|c|c|c|}
\hline Plant & Transcriptional Factors & Plant Defense & References \\
\hline Saccharum Spontaneum & $\begin{array}{c}\text { MYB36, MYB48, MYB 54, } \\
\text { MYB61 }\end{array}$ & Drought stress resistance & [30] \\
\hline Arabidopsis thaliana & MYB 28, MYB29 & ammonium stress & {$[62]$} \\
\hline Plant roots & $\begin{array}{c}\text { MYB41, MYB53, MYB93, } \\
\text { MYB92 }\end{array}$ & Forming protective barrier against biotic and abiotic & [63] \\
\hline Saccharum Spontaneum & MYBs & resistance against mosaic diseases & [30] \\
\hline Solanum lycopersicum & SlMYB52 & $\begin{array}{l}\text { enhancing the tolerance against spider mites by } \\
\text { regulating trichome formation }\end{array}$ & [64] \\
\hline Vitis vinifera $\mathrm{L}$. & $V v M Y B 1, V v M Y B A 3$ & salt stress resistance and drought resistance & [65] \\
\hline Oryza sativa & OsMYB30 & resistance in rice against brown planthopper & [61] \\
\hline Lilium longiflorum & LIMYB305 & positive regulator of thermotolerance & [1] \\
\hline
\end{tabular}

\section{Regulation Mechanism of Flavonoid Biosynthesis Pathway through MYB Transcription Factors}

The flavonoid biosynthetic pathway associated genes are controlled by the collaboration of various families of TFs. The genes responsible for anthocyanin biosynthesis are differentially controlled in monocot and dicots by the MBW complex, which is formed by the physical interaction of R2R3-MYB, bHLH, and WD40 Proteins. This MBW complex stimulates the temporal and spatial expression of structural genes encoding for the biosynthesis of anthocyanin. Anthocyanin biosynthesis controlling in monocot differs from dicots species. MYB and bHLH protein in maize are determined by $P l / C 1$ and $B / R$ families, 
each member of these families has tissues specific pattern. A WD40 transcriptional factor, PAC1 is needed by either B1 or R1 proteins to stimulate the biosynthesis of anthocyanin genes in different tissues (seeds and roots) [66]. In Arabidopsis thaliana, TT2, TT8 and TTG1 activate PA biosynthesis in seeds growth. Whereas TTG1, a WD40 protein, various bHLH and PAP1, PAP2 (MYB) physically interact each other to motivate anthocyanin biosynthesis in vegetative section $[67,68]$.

Various R2R3 MYB (TFs) were recognized from many model plants, including Arabidopsis thaliana and Zea mays are take part in the control of the flavonoid and phenylpropanoid biosynthetic pathway $[2,66,69]$. Recently plant genome-wide surveys provide the opportunities for the identification and isolation of many MYB TFs responsible for the regulation of flavonoid biosynthesis form different plant species, including strawberry, apple, potato, pear, bayberry, grapevine, pear, poplar, purple kale, soybean and cauliflower (Figure 2) [70]. Most of these MYB genes have been functionally characterized by overexpression in host species.

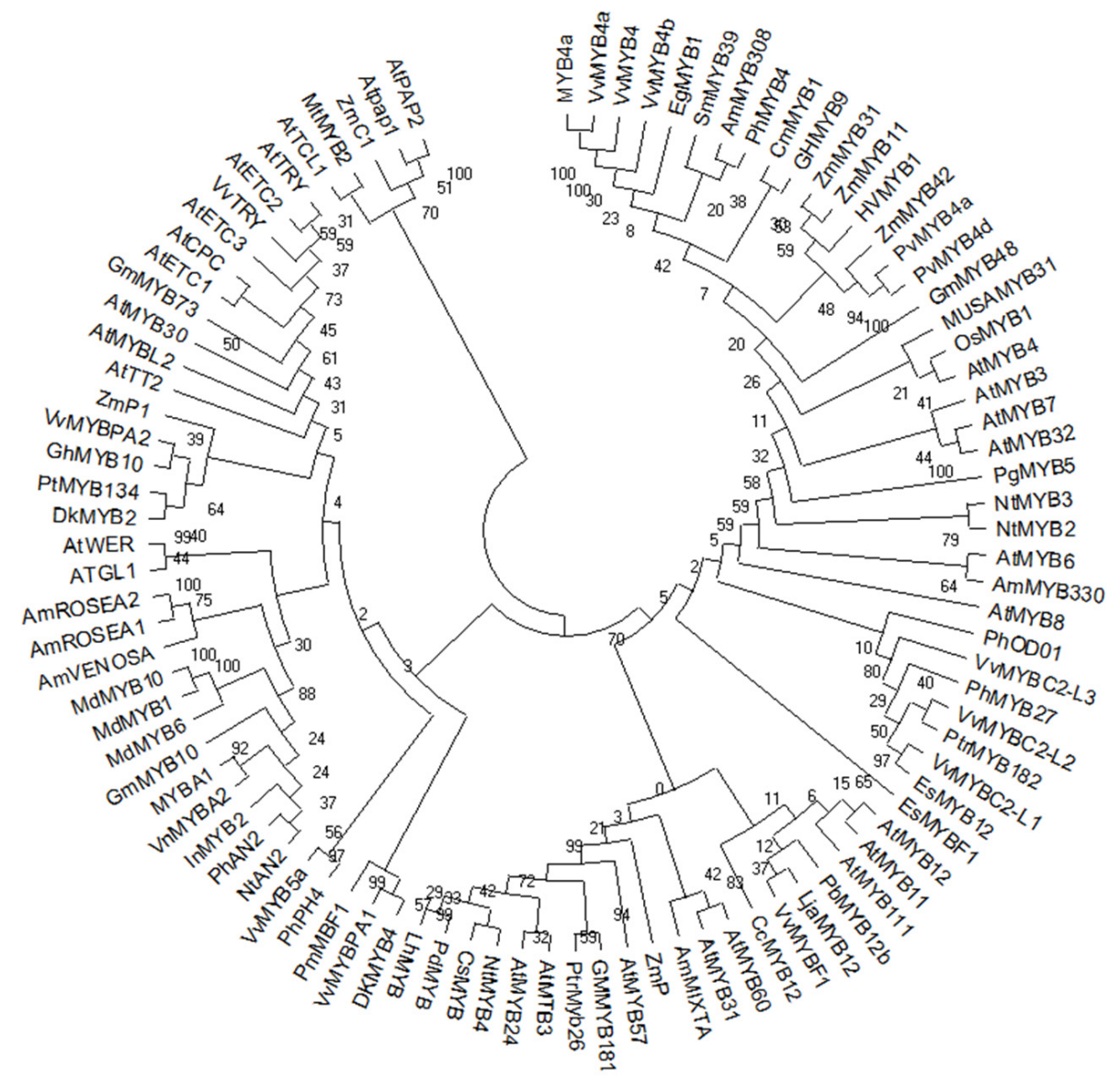

Figure 2. Phylogenetic tree of MYB TFs, which are involved in the regulation of secondary metabolites. 
The anthocyanins exhibited high levels of biological function in plants. It acts as a visual signal to pollinators and provides defense against stresses (biotic and abiotic), including cold tolerance, infection by pathogen, high intensity of light and oxidative damage in plant cells [71-73]. Dietary consumption of anthocyanin has been connected with protection against a broad spectrum of human diseases [74]. Therefore, a high level of anthocyanin accumulation and control are needed for economic as well as scientific significance. R2R3-MYB, bHLH and WD-repeat protein act together to form MBW complex. This transcriptional complex is responsible for anthocyanin biosynthesis regulation. In Eudicots, this development starting in stressed leaves and developing flowers by R2R3 MYB proteins activation. Anthocyanins biosynthesis pathway is a branch of flavonoid pathway that has been extensively studied in petunia (Petunia hybrida) [17], Lily (Asiatic hybrid lilies) [75], Chinese narcissus [12], monkey flower (Mimulus) [76], Anthurium andraeanum [77] and Cymbidium hybrid [78]. In fruits and vegetables, MYB TFs are also well-described in anthocyanin biosynthesis, such as apple and potato [41,79]. The anthocyanin biosynthetic pathway includes structural as well as regulatory genes. Several recent studies indicated that MBW complex activate the expression of structural genes, which are responsible for the accumulation of anthocyanin pathway. R2R3-MYB proteins in the MBW complex generally take part in the accumulation of anthocyanin [80]. In our previous study, NtMYB3 and $N t M Y B 2$ are isolated from Chinese narcissus, which are responsible for the regulation of anthocyanin biosynthesis. Heterologous overexpression of NtMYB2 and NtMYB3 reduced the anthocyanin contents and down-regulate the expression level of genes, including UFGT, ANS and DFR in the transgenic flowers of tobacco [11,12].

\section{The Role of Condensed Tannins in Plants and MYB}

Condensed tannins (proanthocyanidins) are well-known polyphenols with different ecological functions. It is the polymers of flavan-3-ols and the resultant product of flavonoid pathway [81]. PA is the most extensively spread secondary metabolites and is mainly prominent in forest trees and woody plants [82]. In trees, proanthocyanidins are general constituents of vegetative parts which consist of flowers, leaves, bark, seed and roots [83], and provide protection to plants from various abiotic and biotic stressors. The occurrence of proanthocyanidins (PAs) in herbaceous plants is more limited, while they are found in lotus corniculatus and Onobrychis viciifolia $[84,85]$. The accumulations of PAs were observed in seed coat or testa in Glycine max and Arabidopsis thaliana. In Brassica napus, PAs are down-regulated in yellow seed [86]. PAs are also found to be accumulate in monocot species such Chinese narcissus $[87,88]$. PAs have diverse biological functions; they are functionally defined by their capacity to attach and precipitate proteins in solutions, act as antioxidants and as pro-oxidants and provide tolerance to environmental stresses [89,90]. In our previous study, $N t M Y B 3$ and $N t M Y B 2$ are isolated from Chinese narcissus are involved in the regulation of proanthocyanin biosynthesis. The ectopic overexpression of NtMYB2 reduced the PA in transgenic flowers of tobacco by regulating the main key genes $L A R$ and $A N R$. NtMYB3 positively regulates the transcript level of $A N R$ and $L A R$ in transgenic tobacco. The PA contents were higher in NtMYB3 overexpression tobacco flowers as compared to wild [11,12]. In vertebrate herbivores with the naturally acidic stomach, PA attaches nutritional protein and show anti-nutritive effects when found in high concentrations. The forage legumes with balance PAs concentration reduced the risk of rumen foaming and bloating diseases in grazing cattle [91]. FhMYB5 belong to VvMYB5b subclade accumulate proanthocyanidin and anthocyanin in Freesia hybrida by up-regulating the DFR gene [92]. In ruminants, methane emissions and nematode burden can be minimized by the action of proanthocyanin [93]. Furthermore, the induction of proanthocyanin biosynthesis plays a key role in plant defense [94]. 


\section{Physiological and Metabolic Regulation of Phenolic Acid and Terpenoids through MYB Transcription Factors}

Phenolic acids are universal secondary metabolites in plants, which play a very important physiological and metabolic role in the entire plant life cycle [95]. Phenolics regulate the various physiological process, which is associated with plant development and growth, cell division, seed germination and photosynthetic pigmentation [96]. Plant shows increased biosynthesis of phenolic and flavonoids under the conditions of abiotic stress, which support the plant to cope with environmental constraints. Phenylpropanoid biosynthetic pathway is stimulated under the condition of abiotic stress, which facilitates the accumulation of different phenolic compounds that have the capacity to scavenge harmful reactive oxygen species. Depending on their carbon skeleton, it can be divided into two main groups, such as the hydroxycinnamic acid group and the hydroxybenzoic acid group. Such compounds are of great medicinal significance; several of them are effective antioxidants, and many others are recognized as anti-inflammatory, anticarcinogenic, antiviral and antibacterial functions [97,98]. MYB TFs are the most significant gene family, which regulate the phenolic biosynthetic pathway as previously identified in various species. PAL, C4H and $4 C L$ are very important enzymatic genes, which participate in the polyphenolic biosynthetic pathway (Figure 1). Ding, et al. [99] described that when SmMYB36 overexpressed in Salvia miltiorrhiza (hairy roots), it stimulated the accumulation of tanshinones, but repressed the flavonoid and phenolic acid biosynthesis. A novel gene SnMYB2 increased the biosynthesis of salvianolic acid in the roots of salvia, which is the potential medicinal herb [100]. SmMYB1, which are responsive to methyl jasmonate, enhance the biosynthesis of phenolic acid [101]. SmMYB2 is another novel gene that regulates the salvianolic acid in Salvia miltiorrhiza, and enhanced its biosynthesis [100]. When AtPAP1 overexpressed in Brassica napus increases the antioxidant and sinapic acid content of the leaves. Furthermore, the expression level of genes participated in flavonoid and a phenolic acid biosynthetic pathway were stimulated [102]. ZmMYB-IF35, from maize, increase chlorogenic and ferulic acid accumulation [103]. AtMYB4, identified from Arabidopsis thaliana, belongs to repressor R2R3-MYB subgroup 4, increased the expression level of $\mathrm{C} 4 \mathrm{H}$ leads to accumulation of sinapate ester in Atmyb4 mutants [104]. Heterologous expression of ROSEA1(snapdragon) and PAP1(Arabidopsis thaliana) increases the level of salvianolic acid and rosmarinic acid $[105,106]$. The overexpression of SmMYB39 (subgroup 4) dramatically reduced the total phenolics and contents of rosmarinic acid, salvianolic acid and 4-coumaric acid, in transgenic lines of Salvia miltiorrhiza by down-regulating the $\mathrm{C} 4 \mathrm{H}$ gene. Furthermore, all of these compounds were rescued, when SmMYB39 was silenced by RNAi [107]. In a recent study, SmMYB2 improved salvianolic acid biosynthesis in Salvia miltiorrhiza, which is a very potential medicinal herb [100].

Tanshinones are the liposoluble and major bioactive compounds usually present in medicinal herb plants, such as salvia miltiorrhiza. Enhancing the production of Tanshinones is critical because of its economic values in human medicine, anti-tumor properties and the curing of cerebrovascular and cardiovascular diseases. Tanshinones has various biological functions, including antiallergic effects, anti-inflammation, anti-cancer, antioxidant and anti-microbial $[108,109]$. Tanshinones are the diterpenoids, which are synthesized via two different pathways, such as the MEP pathway and MVA pathway, which are localized in plastids and cytosol, respectively (Figure 3). SmMYB98, belong to subgroup 22, predominantly expressed in lateral roots of salvia miltiorrhiza improved the salvianolic acids and tanshinones in their hairy roots [110]. In Danshen, SmMYB98b increased the production of Tanshinones [111]. A significant increase in the production of Tanshinones upon the overexpression of SmMYB9b in medicinal plants is observed in Figure 3 [112]. 


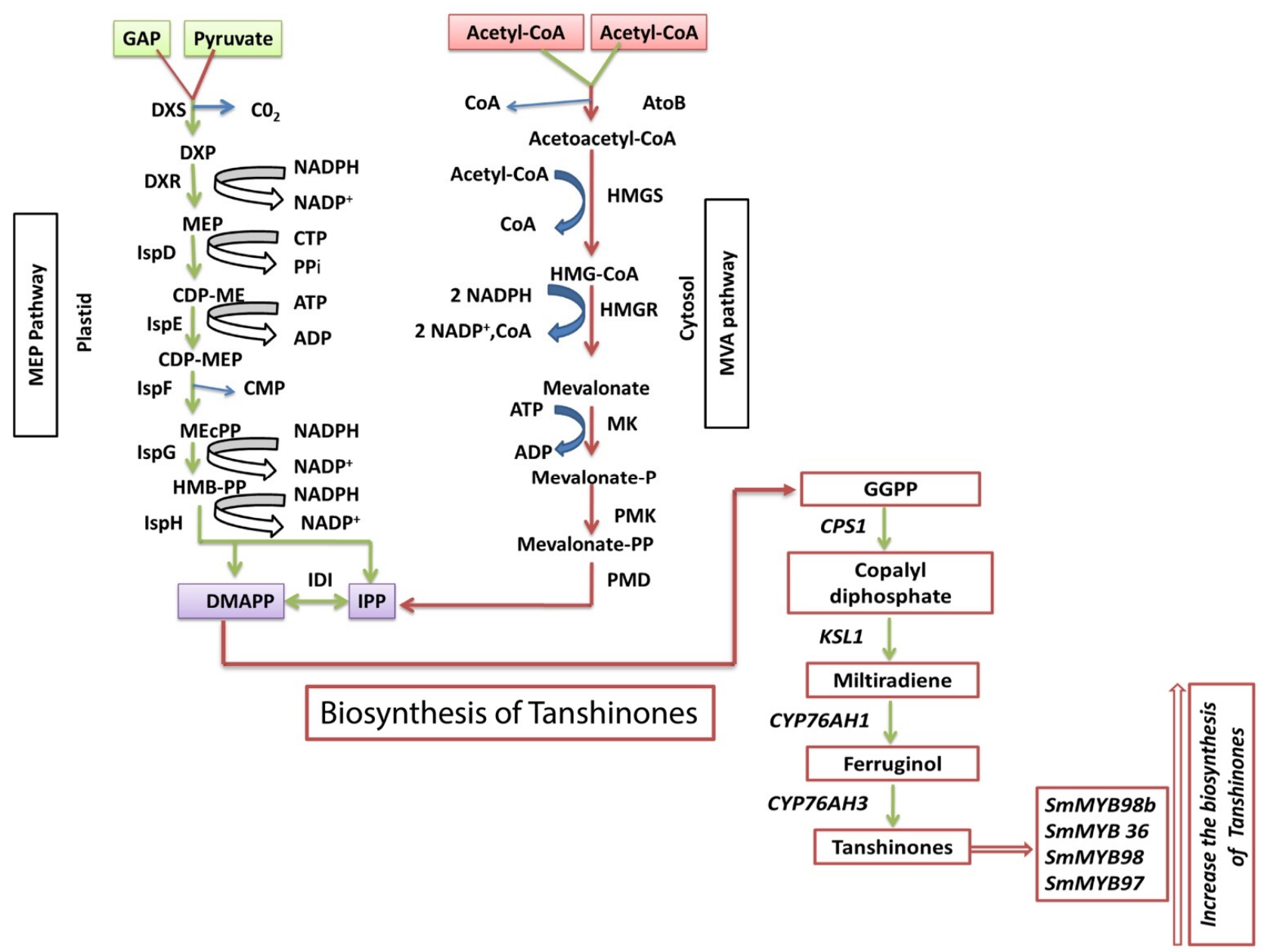

Figure 3. General Biosynthetic pathway of terpenoids (Tanshinones). The red arrow indicates the improvement of biosynthesis of tanshinones through the positive regulation of R2R3 MYB TFs. 2-C-methyl-D-erythritol 4-phosphate (MEP) biosynthetic pathway takes place in the cytosol and mevalonate (MVA) biosynthetic pathway takes place in plastid areas. SmMYB98b, SmMYB36, SmMYB98 and SmMYB97 positively regulate the tanshinones biosynthesis.

\section{The Flavonol Biosynthetic Pathway Is Regulated by MYB Transcription Factor}

The flavonols are colorless and among the most plentiful flavonoids in plants, generally exist in mono-, di-, or triglycerides form [113]. Flavonol regulates several biological functions in plants, such as auxin transport regulation $[15,114]$, the process of fertilization in higher plants, and it is a natural antioxidant [115]. The biosynthetic pathway of flavonol is controlled by MYB protein alone, or acts on the MBW complex or establishment of an MYB-bHLH dimer. A novel gene $P b M Y B 12 b$, positively regulates the flavonol accumulation in pear by up-regulating the PbFLS and $P b C H S b$ genes [15]. R2R3-MYB transcriptional factor CcMYB12 isolated from Cynaracardunculus var. scolymus and functionally characterized in Arabidopsis. Ectopic overexpression of CcMYB12 activates the levels of gene expression involved in flavonol biosynthesis, ultimately lead to flavonol accumulation in Arabidopsis [116]. In Arabidopsis MYBTFs (AtMYB111, AtMYB11, and AtMYB12) individually accomplished for motivating the genes encoding for flavonol synthase (FLS). The expression of $A t M Y B 12$ and AtMYB111 is spatially differentiated in the emerging seedling. The AtMYB12 regulates flavonol synthesis generally in the root. Whereas, it was found that AtMYB111 is dynamic in the cotyledons [113]. Another R2R3-MYB transcriptional factor denoted as $P b M Y B 12 b$, which belongs to subgroup 7, positively regulates the flavonol accumulation in pear fruits [15]. In grapevine, transient assay indicated that VvMYBF1 controls the expression of FLS1 and many other promoters of Arabidopsis and grapevine. 
In M. truncatula, R2R3-MYB134 positive regulator flavanol biosynthesis [117]. Ectopic overexpression of LjaMYB12 from Lonicera japonica enhances the flavonol accumulation in the model plant Arabidopsis [7]. Both GtMYBP3 and GtMYBP4 genes are isolated from the Japanese gentian (Gentiana triflora). When these genes are over-expressed in model plants Arabidopsis, the increase the transcript level of genes encoding for flavonol biosynthetic pathway. Furthermore, flavonol contents were increased in the seedling of Arabidopsis transgenic plants [118]. These previously functionally characterized R2R3-MYB TFs belong to subgroup 7 containing $[\mathrm{K} / \mathrm{R}][\mathrm{R} / \mathrm{x}][\mathrm{R} / \mathrm{K}] \mathrm{xGRT}[\mathrm{S} / \mathrm{x}][\mathrm{R} / \mathrm{G}] \mathrm{xx}[\mathrm{M} / \mathrm{x}] \mathrm{K}$ and $([\mathrm{W} / \mathrm{x}][\mathrm{L} / \mathrm{x}] \mathrm{LS})$ motifs at C-terminal (Figure 4B). StMTF1 (Solanum tuberosum) and VvMYB5a (grapevine) belong to subgroup 6 and 27 respectively, involved in the accumulation of flavonol contents [119,120]. MdMYB3 gene belong to subgroup 4 activate the flavonol biosynthesis [121]. In our previous study, NtMYB3 and NtMYB2 are isolated from Chinese narcissus are responsible for the regulation of flavonol biosynthesis. Ectopic overexpression of NtMYB2 and NtMYB3 reduced the flavonol contents by suppressing the FLS in the transgenic flowers of tobacco [11,12]. In Maize C1 (R2R3 MYB TFs), that functions to accumulate flavonol biosynthesis.

(A) Atmyв21

AtMYB57

PtrMYB26

Consensus

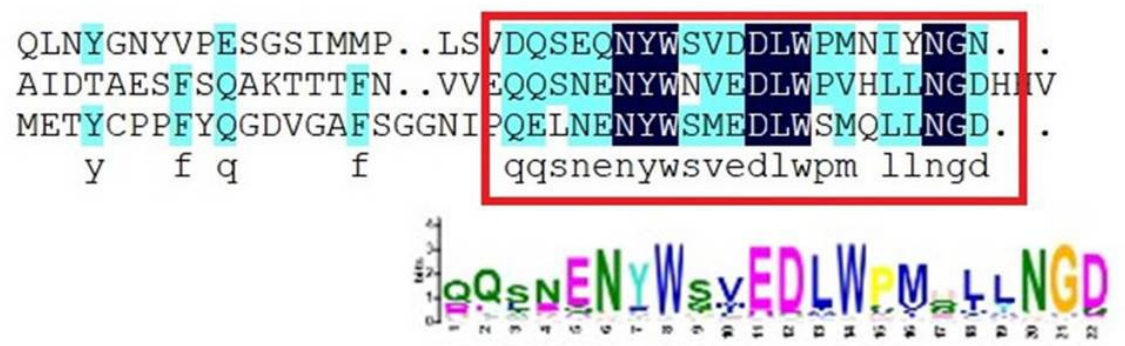

(B) AtMYB11

AtMYB12

AtMYB111

ESMYBF 1

LjaMYB12

Consensus

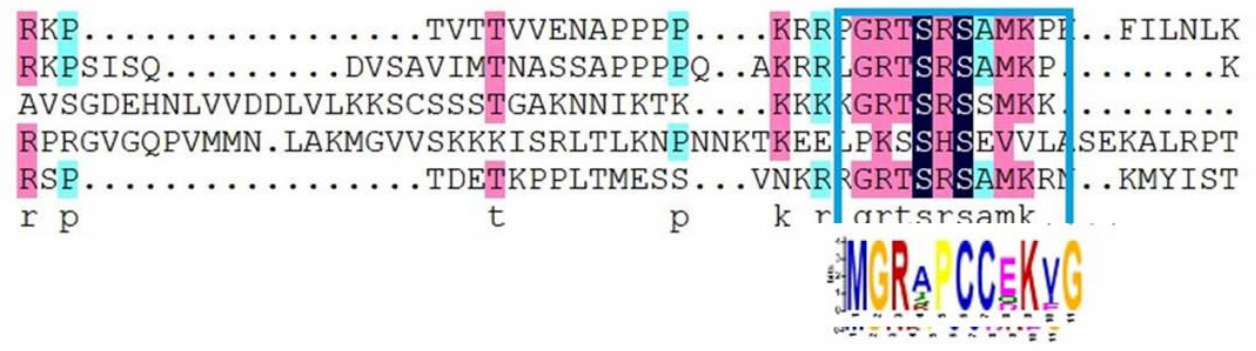

(c) NtMYB3

ACMYB 1

AtMYB32

MdMYB1 6

GmMYB 54

PgMYB 1

SMMYB39

VVMYB4A

CMMYB1

AtMYB 4

MdMYB 1

Consensus

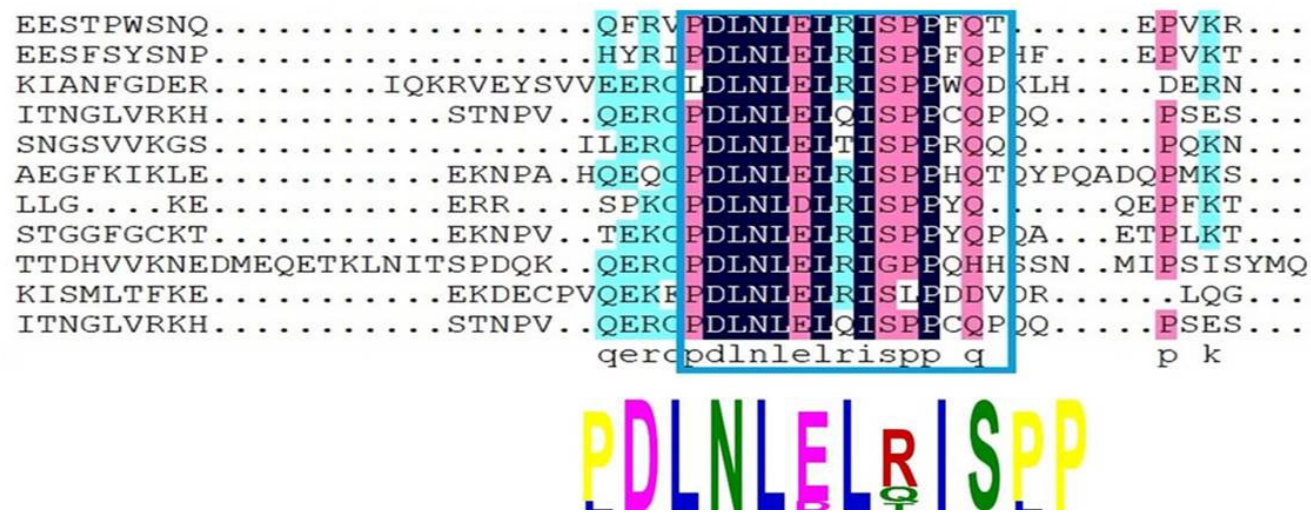

Figure 4. The conserved motif at C-terminal. (A) the conserved motif that regulates the anther development; (B) this conserved motif regulate the flavonol biosynthesis; (C) C2 motif (LxLxLx), which has repressive activities.

\section{Expression Pattern of MYB Transcription Factors in Specific Tissues}

MYB TFs are constitutively expressed in vegetative and reproductive parts of the plant. Several MYB TFs, which show various expression patterns in specific tissues, are functionally characterized. Some of these MYB TFs, expressed in many tissues and some are 
involved in the tissue-specific expression. AtMYB21 and AtMYB24, PsMYB26, AmMYB308, $A m M Y B 340$ are mainly expressed in flowers (Figure 4A). The expression level of GbMYBF2 was higher in roots as compared to the stem, fruits and leaves [122]. StMYB12A mainly expressed in flowers [123]. The highest expression of GbMYBR1 in Ginkgo was detected in leaves [124]. Maximum expression levels of NtMYB5 were detected in perianth and corona of Chinese narcissus [125]. The expression level of SmMYB86 were observed in peel, stem and leaves [126]. The transcript level of VvMYB4-like gene was observed in various parts, such as flower, skin, leaves and roots in grapevine [127]. CsMYB1 from Crocus sativus is involved in stigma development and showed expression in stigma tissues [128]. The MYB genes, including AtMYB26, AtMYB57 and AtMYB103, are identified [129,130]. In poplar, the existence of PtrMYB57 was found in all tissues, but not in roots [131]. In Arabidopsis thaliana, the down-regulation of AtMYB103 resulted in aberrant pollens and early tapetal degeneration. In the same way, AtMYB32 has also been vigorously expressed in papillae, stigma, lateral root primordial and tapetum [130,132]. NtMYB2 from Chinese narcissus has been involved in the suppression of flavonoid biosynthesis, especially anthocyanin. Our recent study indicated that NtMYB2 and NtMYB3 are mainly expressed in the flowers [11,12].

Tissue-specific regulation has also been reported in other plants, HbMYB1 detected in latex, bark, and leaves of rubber tree while in trapping panel dryness trees, its expression reduced greatly [133]. The expression of AtMYB101 was limited only to hypocotyls hook and subapical cells of plant. However, in many tissues, AtMYB65 and AtMYB33 were co-expressed. The expression pattern of the R2R3-MYB gene is quite unique as indicated by AtMYB102 in Arabidopsis was down-regulated in stem and up-regulated in young flowers, leaf, and root on treating with ABA [134,135]. GhMYB9 and GhMYB7 have been detected in fibers and flowers, and the expression of these gene are developmentally regulated in fibers [136]. Moreover, previous investigations have proposed the involvement of GaMYB in seed development, another development, floral initiation and stem elongation [137], it showed a high-level of expression in grass L. temulentum in the stamen primordia and floral meristem. In our recent study, we found that NtMYB4 is involved in development and mainly expressed in flowers (data unpublished). In soybean, GmMYBJ7 and GmMYBJ6 were only expressed in stem and leaf, which shows that MYB TF's common characteristic may represent different pattern among higher plants [138].

\section{Regulation of Flavonoid Biosynthesis}

Recently, we investigated NtMYB2 and NtMYB3, which are isolated from Chinese narcissus and belong to subgroup 4. Ectopic overexpression of these genes in tobacco reduces flavonoid biosynthetic pathway genes that are controlled through the interaction of various families of TFs. The genes which are responsible for anthocyanin biosynthesis are differentially controlled in monocot, as well as dicots species by MBW complex. This MBW complex activates the temporal and spatial transcript of genes (structural), encoding for anthocyanin accumulation. Anthocyanin biosynthesis regulation in monocot differs from dicots species. Several R2R3 MYB (TFs) were recognized in many plants, including Petunia hybrida, Arabidopsis thaliana and Zea mays, which are responsible for flavonoid biosynthesis regulation. Recently plant genome-wide survey provide the opportunities for the identification and isolation of many MYB TFs responsible for regulation of flavonoid biosynthesis form various plant species, including eggplant, strawberry, apple, potato, pear, bayberry, grapevine, pear, poplar, purple kale, soybean, cauliflower and Chinese narcissus [12]. Most of these MYB genes have been functionally characterized by overexpression in host species.

\section{MYB Transcription Factors Act as Repressors through C2/ERF/TLLFR Motif}

MYB suppressor has conserved the R2R3 region at the end of N-terminal, which also contained the conserved signature of [D/E]Lx2[R/K]x3Lx6Lx3R inside the R3-domain, which interact with $b H L H$ cofactor and performed specific functions [139]. For example, MdMYB15L could not perform its functional activities without $b H L H$ cofactors [140]. 
MYB TFs show highly divergence at C-terminal domain, which determines the particular functions. Based on diverge protein sequence at $\mathrm{C}$-terminal, they have been divided into subgroups about 22. The proteins of Subgroup 4 function as transcriptional repressors of the phenylpropanoid pathway, and also suppress the key enzymes involved in their metabolic activities. Phylogenetic tree analysis (Figure 5) indicated that R2R3-MYB transcription factor could be divided into three clades, including FaMYB1-Like, MYB4-Like and CPC-like clades (Figure 5). NtMYB3 and NtMYB2 anthocyanin repressors are more closely related to the MYB4-Like clade [12]. PtrMYB182 is closely related to the FaMYB1-like clade. The MYB repressor belong to MYB4-Like clade contain C1 (LlsrGIDPxT /sHRxI /L), also called GIDP motif, which is also found in subgroup 8,9 and 11 possess activator activities and C2 (LxLxL) or (pdLNLD/ELxiG/S) motif (Figure 2), which is also called EAR motif, and some have C1, C2, C3(CX1-2CX7-12CX2C) and C4 (FLGLx4-7V/LLD/GF/YR/Sx1LMK) motifs depend upon the length of amino acids, but these motifs are absent in FaMYB1 like Clade, which usually possess TLLLFR motif at their C-terminus (Figure 2). For example, a similar motif was found in VvMYB4-like protein [127]. Another difference in the signature of conserved sequence between AtMYB4-like clade FaMYB1-like clade is the DNEI and DNEV, respectively, which are usually present in R3 domain. The potential and the importance of DENI or DNEV conserved signature in R2R3-MYB repressor proteins are needed for further investigation. The C-terminus of MYB TFs show divergent. They are considered to be accountable for various regulatory functions. Moreover, MYB repressors belong to AtMYB4-like clade directly binds on the promoters of targets genes for example MdMYB16, while MYB repressor members of FaMYB-like clade need MBW complexes for their function, for example PhMYB27 [141,142]. SmMYB86 gene was isolate from eggplant and its overexpression reduced the anthocyanin. SmMYB86 directly binds on promoters and repress the activities of ANS, F3H and CHS [126].

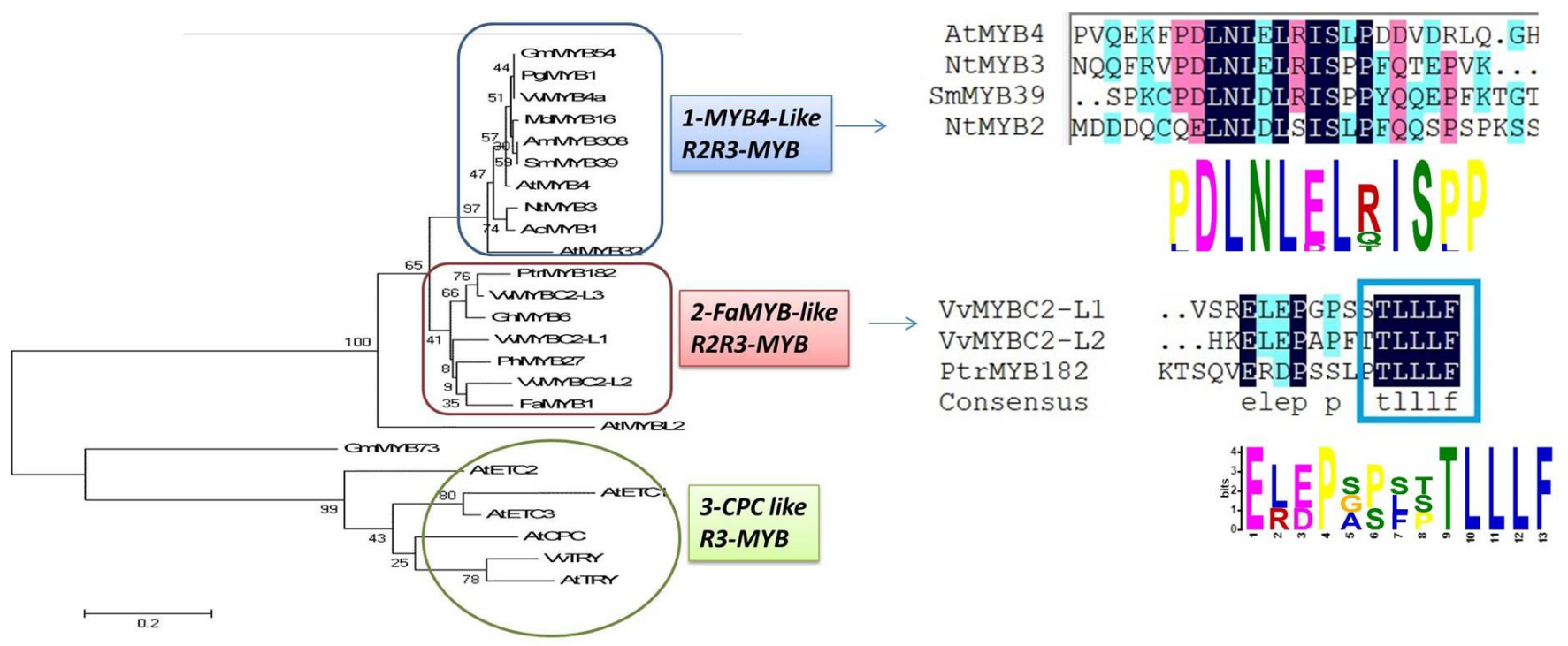

Figure 5. Phylogenetic relationship and signature of conserved protein motifs in R2R3 and R3 MYB repressors connected to phenylpropanoid biosynthesis.

From Antirrhinum majus, AmMYB308 and AmMYB330, adversely affected lignin and phenolic acids biosynthesis through its overexpression in tobacco. Furthermore, key enzymes, including $4 C L, C 4 H$ and $C A D$ encoding for the phenylpropanoid pathway, were downregulate [143]. Overexpression of ZmMYB42 and ZmMYB31 in Arabidopsis thaliana reduced lignin contents [144]. In Arabidopsis, AtMYB32 and AtMYB4 knockout mutant enhanced the yield of lignin and sinapate esters by increasing the expression level of the $\mathrm{C} 4 \mathrm{H}$ gene. In addition, MYB4 acts as a repressor of phenylpropanoid metabolisms by downregulating the expression of genes encoding arogenate Dehydratase 6, which cat- 
alyzes the final step in phenylalanine biosynthesis [132,145]. MdMYB6 isolated from apple, reduced the anthocyanin accumulation upon its overexpression in Arabidopsis thaliana. Overexpression of AtMYB60 in lettuce repress the anthocyanin accumulation by strongly down-regulate the dihydroflavonol 4-reductase (DFR) gene [146]. A dramatic reduction of anthocyanin and flavonols accumulation were observed in transgenic tobacco when FaMYB1 was overexpressed in tobacco. Proanthocyanidins were also reduced in the leaves of lotus [147]. Albert et al. (2014) described when FcMYB1 was suppressed in strawberry fruits, the accumulation of anthocyanin to increase in strawberry fruits. When PhMYB27 repressed by RNA interference increased the anthocyanin accumulation in vegetative tissues and flowers of Petunia. Furthermore, the suppressive action of PhMYB27 decreased by cut of DLNxxP -type EAR motif. In grapevine, VvMYBC2-L1 is a novel locus, down-regulate the expression of proanthocyanidins pathway-related gene and decreased the amount of PA by overexpressing in hairy root [148]. AtMYB7, reduce the biosynthesis of flavonol though directly targeting genes, such as UGT and DFR, and negatively regulate the seed germination [149,150]. CmMYB1, from Chrysanthemum, recognized as repressor candidate, negatively regulate the lignin and flavonoid pathway, reduced the flavonoid and lignin contents in Arabidopsis thaliana [151]. Overexpression of SmMYB39 in Salvia strongly reduced the total phenolics, salvianolic acid A and B, 4-coumaric acid and 4-coumaric acid through downregulation of tyrosine aminotransfersase (TAT) and 4-hydroxylase $(\mathrm{C} 4 \mathrm{H})$ genes [107]. In poplar plants, PtrMYB57 suppress the anthocyanin and proanthocyanidin accumulation [152]. TaMYB4 (from wheat) reduced the expression of cinnnamoyl-CoA reductase (CCR) and cinnamyl alcohol dehydrogenase(CAD) in transgenic tobacco [153]. In addition, microRNA 858 and microRNA156 have negative effect on anthocyanin biosynthesis by expressing their target MYB gene [154] (Table 2).

Table 2. MYB TFs involved in plant general flavonoid pathway and act as repression functions.

\begin{tabular}{|c|c|c|c|c|c|}
\hline Species & Group & Protein/Gene & Target Gene & Functions & References \\
\hline Chrysanthemum & R2R3-MYB & CmMYB8 & $\begin{array}{c}\text { PAL, C4H, 4CL1, } \\
\text { HCT, CCR1, } \\
\text { AOMT1, COMT }\end{array}$ & $\begin{array}{l}\text { Reducing the contents of Lignin } \\
\text { and flavonoids }\end{array}$ & [155] \\
\hline Petunia hybrida & R2R3-MYB & $\mathrm{PhPH} 4$ & $\begin{array}{l}F 3 H, F 3^{\prime} H, F 3, F 3^{\prime} \\
5^{\prime} H\end{array}$ & Anthocyanin Repressor & [69] \\
\hline Citrus & R2R3-MYB & CsMYB3 & CsRuby1/CsbHLH1 & Reduced the anthocyanin & [156] \\
\hline Pear & R2R3-MYB & PbMYB120 & UFGT & $\begin{array}{c}\text { Negative regulator of } \\
\text { anthocyanin biosynthesis }\end{array}$ & [157] \\
\hline Arabidopsis & R2R3-MYB & MYB4 & ADT6 & Phenylpropanoid metabolisms & [145] \\
\hline Vitis vinifera & R2R3-MYB & VvMYB4-like & ANS, DFR, UFGT & Anthocyanin repressor & [127] \\
\hline Vitis vinifera & R2R3-MYB & VvMYBC2L2 & $\begin{array}{l}\text { DFR, UDP, UFGT, } \\
\quad \text { AN1a, AN1b }\end{array}$ & $\begin{array}{c}\text { Negative regulator of } \\
\text { anthocyanin biosynthesis }\end{array}$ & [158] \\
\hline Glycine max & R2R3-MYB & GmMYB100 & $\begin{array}{c}\text { CHS, CHI, F3H, } \\
\text { ANS }\end{array}$ & $\begin{array}{l}\text { Negatively regulate flavonoid } \\
\text { biosynthesis }\end{array}$ & [159] \\
\hline Ginkgo biloba & MYB & GmMYBR1 & GL1 & $\begin{array}{l}\text { Anthocyanin, Lignin, Flavonol } \\
\text { and Proanthocyanin reduced }\end{array}$ & [124] \\
\hline Banana & R2R3-MYB & MaMYB4 & CHS, DFR, ANS & Anthocyanin repressor & [160] \\
\hline Malus domestica & R2R3-MYB & $\begin{array}{l}\text { MdMYB6, } \\
\text { MdMYB16 }\end{array}$ & ANS, UFGT & $\begin{array}{l}\text { Reduce the contents } \\
\text { anthocyanin }\end{array}$ & {$[141,161]$} \\
\hline Populus tremuloides & R2R3-MYB & PtrMYB57 & $\begin{array}{l}\text { CHS, 4CL, DFR, } \\
\text { ANS, ANR, LAR }\end{array}$ & $\begin{array}{l}\text { Reduction of anthocyanin and } \\
\text { Proanthocyanidin }\end{array}$ & [152] \\
\hline Populus tremuloides & R2R3-MYB & PtrMYB182 & ANR1, CHS1, DFR & $\begin{array}{l}\text { Down-regulation of } \\
\text { anthocyanin and } \\
\text { Proanthocyanidin }\end{array}$ & [132] \\
\hline Arabidopsis & R2R3-MYB & AtMYB3 & $\mathrm{C} 4 \mathrm{H}$ & Phenylpropanoid repressor & [162] \\
\hline
\end{tabular}


Table 2. Cont.

\begin{tabular}{|c|c|c|c|c|c|}
\hline Species & Group & Protein/Gene & Target Gene & Functions & References \\
\hline Arabidopsis & R2R3-MYB & AtMYB60 & DFR & Anthocyanin repressor & [146] \\
\hline Arabidopsis & R2R3-MYB & AtMYB7 & UGT, DFR & Suppression of flavonol & [149] \\
\hline Arabidopsis & R3-MYB & $\mathrm{CPC}$ & DFR, LDOX & $\begin{array}{l}\text { Down regulation of } \\
\text { anthocyanin }\end{array}$ & [163] \\
\hline Arabidopsis & R3-MYB & AtMYBL2 & DFR, LDOX & Anthocyanin Repressor & [164] \\
\hline Fragaria ananassa & R2R3-MYB & FaMYB1 & DFR, ANS, ANR & $\begin{array}{l}\text { Reduce the anthocyanin and } \\
\text { Flavonol, Proanthocyanidins }\end{array}$ & {$[147,165]$} \\
\hline Fragaria chiloensis & R2R3-MYB & FcMYB1 & LAR, ANS, ANR & Anthocyanin repressor & [166] \\
\hline Petunia hybrida & R2R3-MYB & PhMYB27 & $A N S, F 3^{\prime} 5^{\prime} H, D F R$ & Anthocyanin repressor & [142] \\
\hline Freesia hybrida & R3-MYB & FhMYBx & & Anthocyanin repressor & [167] \\
\hline Vitis vinifera & R2R3-MYB & VvMYBC2-L1 & & Proanthocyanidins & [168] \\
\hline $\begin{array}{l}\text { Chrysanthemum } \\
\text { morifolium }\end{array}$ & R2R3-MYB & CmMYB1 & $\begin{array}{l}\text { CHS, CHI, FLS, } \\
\text { DFR }\end{array}$ & $\begin{array}{l}\text { Repressor of lignin and } \\
\text { flavonoid }\end{array}$ & [151] \\
\hline Salvia miltiorrhiza & R2R3-MYB & SmMYB39 & $\mathrm{C} 4 \mathrm{H}, \mathrm{TAT}$ & Reduce the total phenolics & [107] \\
\hline Grape hyacinth & R3-MYB & MaMYBx & DFR, ANS & Anthocyanin repressor & [169] \\
\hline Narcissus tazetta & $\begin{array}{l}\text { R2R3- } \\
\text { MYB }\end{array}$ & NtMYB2 & ANS, UFGT & $\begin{array}{l}\text { It reduced the anthocyanin } \\
\text { contents and flower pigments }\end{array}$ & [11] \\
\hline Narcissus tazetta & $\begin{array}{l}\text { R2R3- } \\
\text { MYB }\end{array}$ & NtMYB3 & DFR, UFGT, ANS & $\begin{array}{l}\text { It reduced the anthocyanin and } \\
\text { flavonol contents. It strongly } \\
\text { decreased the flower pigments }\end{array}$ & [12] \\
\hline Populus trichocarpa & R3-MYB & PtrRML1 & DFR, UF3GT & Anthocyanin reduced & [170] \\
\hline Chinese Narcissus & R2R3-MYB & NtMYB5 & $D F R, U F G T$ & Suppressor of Anthocyanin & [125] \\
\hline Iochroma & R3-MYB & $M Y B L 1$ & $\begin{array}{l}\text { DFR, ANS, } \\
\text { CHS, F3H }\end{array}$ & Losses of floral pigmentation & [171] \\
\hline
\end{tabular}

The members of CPC-like clade contain only single R3 repeat, belong to one of 12 different subgroups, which is determined on the base of the conserved motif. The phylogenetic tree divided the R3-MYB repressor into two further subclades, including CPC-like and AtMYBL2-like, and showed evolutionary derivation from each other (Figure 4). The members of R3-MYB belong to CPC-like clade included in a single clade, showed clear divergence from AtMYBL2 clade and R2R3-MYB repressors clade. The at MYBL2-like clade is closely related to the R2R3-MYB repressor, possesses TLLLFR repressive motif at the Cterminus, but repress transcriptional mechanisms are different from CPC-like clade. WxM motif, involved in cell movement, is present in CPC-like clade but absent in AtMYBL2-like clade. The CPC-like repressors do not contain repressive motif and considered to be act as repressors through competing for $b H L H$ cofactor with MYB activators. They interact with $b H L H$ cofactors in competitive way to inhibit the creation of MBW complex. Therefore, they negatively control anthocyanin biosynthesis [71]. The evidence from the recent studies showed that R3-MYB suppressors negatively control the anthocyanin biosynthesis like R2R3 MYB suppressors. IlMYBL1, is a novel R3-MYB transcriptional repressor, which reduced floral pigmentation in Iochroma [171]. In Arabidopsis, ETC1 was concerned with the down regulation of anthocyanin [163,172]. In tomato, AtMYBL2 encodes an R3-MYB protein that regulates the flavonoid biosynthesis. It comprises of a single repeat and shows resemblance with the R2R3-MYBs, which contrasts with other members of R3-MYBs. In the mutant seedling of Arabidopsis thaliana, anthocyanin accumulation was improved due to the loss of MYBL2 activity. Moreover, overexpression of AtMYBL2 in seeds led to the suppression of proanthocyanidin accumulation [173]. AtMYBL2 showed the C-terminal TLLLFR motif in their protein, which contributes to suppressive activities $[173,174]$. MYBX 
and PhMYB27, from Petunia encode a R3-MYB protein suppress the anthocyanin accumulation [163] (Table 2).

\section{Conclusions and Future Perspective}

The MYB transcription factor family is significant in the regulation of bioactive compounds through phenylpropanoid and flavonoid biosynthetic pathway in plants. Generally, it seems that the MYB repressors have more extensive effects than the corresponding MYB activators. Several studies of MYB suppressors exploiting overexpression in heterologous model plant systems, but it is important to authenticate effects using more direct analyses. To date, the role of the conserved motif of repression in MYB TFs is little known. Theses motifs bind and recruits co-repressors or other regulatory proteins for proper functions. Further studies need to emphasis testing the promoters and bHLH binding capacity of more diversity of MYB repressors. Recognizing suppressor binding targets on a whole-genome scale using ChIP-sequence offers further facts on targets. Eventually, a comprehensive understanding of MYB repressors will assist us to better understand the fine transcriptional regulation of the phenylpropanoid pathway and how they facilitate responses to environmental stress. The regulatory system of transcriptional repressors and activators regulating anthocyanin biosynthesis is conserved within monocot species. R3-MYB looks a potentially valuable target for floral color modification in horticulture plants. S. miltiorrhiza is a potential medicinal plant, and in order to increase its clinical demand, we need to apply recent advanced metabolic engineering approaches to improve and enhance the biosynthesis of bioactive medicinal compounds.

Several studies on the role of MYB TFs in the regulation of secondary metabolites and bioactive compounds have been done in plants. There is no study in its role in microorganisms (bacteria and yeast) and microalgae. Microalgae has great potential as an expression platform for recombinant proteins. Photosynthetic Microalgae, especially Chlamydomonas reinhardtii, is considered as the model host organisms for heterologous protein production, including pharmaceutical products, vaccines, fuels alternative, cosmetics, terpenoids and secondary metabolites. We suggest that there should be more focus on investigating the role of MYB TFs in microalgae for future perspectives, especially regarding the pharmaceutical and food industries. Furthermore, the role of micro-RNA and post translational modification still concern questions to comprehensively understand MYB repressors regulation mechanisms.

Author Contributions: M.A., conceptualization, software, formal analysis, data curation, writingOriginal draft preparation. L.C., data curation, writing-original draft preparation. Y.X., writingreview and editing. J.W., data curation. H.L., writing-review and editing. Q.W., writing-review and editing. L.Z., writing-review and editing, conceptualization, supervision. Z.H., supervision, validation, writing-reviewing and editing, conceptualization, funding acquisition, resources, investigation. All authors have read and agreed to the published version of the manuscript.

Funding: This work was supported by National Natural Science Foundation of China (32050410303, 41876188,), Chinese National Key R and D Project for Synthetic Biology (2018YFA0902500 Guangxi Innovation Drive Development Special Fund (Gui Ke AA18242047) Funding for the Construction of Southern Marine Science and Engineering Guangdong Laboratory (Guangzhou) and Grant Plan for Demonstration Project for Marine Economic Development in Shenzhen to Zhangli Hu.

Institutional Review Board Statement: Not applicable.

Informed Consent Statement: Not applicable.

Data Availability Statement: Not applicable.

Conflicts of Interest: There is no conflict of interest. 


\section{References}

1. Wu, Z.; Li, T.; Liu, X.; Yuan, G.; Hou, H.; Teng, N. A novel R2R3-MYB transcription factor LlMYB305 from Lilium longiflorum plays a positive role in thermotolerance via activating heat-protective genes. Environ. Exp. Bot. 2021, 184, 104399. [CrossRef]

2. Stracke, R.; Werber, M.; Weisshaar, B. The R2R3-MYB gene family in Arabidopsis thaliana. Curr. Opin. Plant Biol. 2001, 4, 447-456. [CrossRef]

3. Xiang, X.-J.; Sun, L.-P.; Yu, P.; Yang, Z.-F.; Zhang, P.-P.; Zhang, Y.-X.; Wu, W.-X.; Chen, D.-B.; Zhan, X.-D.; Khan, R.-M.; et al. The MYB transcription factor Baymax1 plays a critical role in rice male fertility. Theor. Appl. Genet. 2020, 134, 453-471. [CrossRef]

4. Liu, J.; Osbourn, A.; Ma, P. MYB Transcription Factors as Regulators of Phenylpropanoid Metabolism in Plants. Mol. Plant 2015, 8 , 689-708. [CrossRef]

5. Cao, Y.; Li, K.; Li, Y.; Zhao, X.; Wang, L. MYB Transcription Factors as Regulators of Secondary Metabolism in Plants. Biology 2020, 9, 61. [CrossRef]

6. Paauw, M.; Koes, R.; Quattrocchio, F.M. Alteration of flavonoid pigmentation patterns during domestication of food crops. J. Exp. Bot. 2019, 70, 3719-3735. [CrossRef] [PubMed]

7. Qi, X.; Fang, H.; Chen, Z.; Liu, Z.; Yu, X.; Liang, C. Ectopic Expression of a R2R3-MYB Transcription Factor Gene LjaMYB12 from Lonicera japonica Increases Flavonoid Accumulation in Arabidopsis thaliana. Int. J. Mol. Sci. 2019, 20, 4494. [CrossRef] [PubMed]

8. Allan, A.C. Domestication: Colour and Flavour Joined by a Shared Transcription Factor. Curr. Biol. 2019, 29, R57-R59. [CrossRef] [PubMed]

9. Lu, N.; Rao, X.; Li, Y.; Jun, J.H.; Dixon, R.A. Dissecting the transcriptional regulation of proanthocyanidin and anthocyanin biosynthesis in soybean (Glycine max). Plant Biotechnol. J. 2021, 19, 1429-1442. [CrossRef] [PubMed]

10. Koes, R.; Verweij, W.; Quattrocchio, F.M. Flavonoids: A colorful model for the regulation and evolution of biochemical pathways. Trends Plant Sci. 2005, 10, 236-242. [CrossRef] [PubMed]

11. Anwar, M.; Wang, G.; Wu, J.; Waheed, S.; Allan, A.C.; Zeng, L. Ectopic Overexpression of a Novel R2R3-MYB, NtMYB2 from Chinese Narcissus Represses Anthocyanin Biosynthesis in Tobacco. Molecules 2018, 23, 781. [CrossRef]

12. Anwar, M.; Yu, W.; Yao, H.; Zhou, P.; Allan, A.C.; Zeng, L. NtMYB3, an R2R3-MYB from Narcissus, Regulates Flavonoid Biosynthesis. Int. J. Mol. Sci. 2019, 20, 5456. [CrossRef]

13. Cho, J.-S.; Jeon, H.-W.; Kim, M.-H.; Vo, T.K.; Kim, J.; Park, E.-J.; Choi, Y.-I.; Lee, H.; Han, K.-H.; Ko, J.-H. Wood forming tissue-specific bicistronic expression of PdGA20ox1 and PtrMYB221 improves both the quality and quantity of woody biomass production in a hybrid poplar. Plant Biotechnol. J. 2018, 17, 1048-1057. [CrossRef]

14. Bai, J.; Sun, F.; Wang, M.; Su, L.; Li, R.; Caetano-Anollés, G. Correction to: Genome-wide analysis of the MYB-CC gene family of maize. Genetica 2019, 147, 11. [CrossRef] [PubMed]

15. Zhai, R.; Zhao, Y.; Wu, M.; Yang, J.; Li, X.; Liu, H.; Wu, T.; Liang, F.; Yang, C.; Wang, Z.; et al. The MYB transcription factor PbMYB12b positively regulates flavonol biosynthesis in pear fruit. BMC Plant Biol. 2019, 19, 1-11. [CrossRef]

16. Muñoz, C.; Fanzone, M.; Lijavetzky, D. Transcriptional regulation of the anthocyanin biosynthesis pathway in developing grapevine berries in cultivar 'Malbec' by putative R2R3 MYB negative regulators. Sci. Hortic. 2019, 257, 108663. [CrossRef]

17. Wang, Y.; Zhang, F.; Cui, W.; Chen, K.; Zhao, R.; Zhang, Z. The FvPHR1 transcription factor control phosphate homeostasis by transcriptionally regulating miR399a in woodland strawberry. Plant Sci. 2018, 280, 258-268. [CrossRef] [PubMed]

18. Li, J.; Liu, H.; Yang, C.; Wang, J.; Yan, G.; Si, P.; Bai, Q.; Lu, Z.; Zhou, W.; Xu, L. Genome-wide identification of MYB genes and expression analysis under different biotic and abiotic stresses in Helianthus annuus L. Ind. Crop. Prod. 2019, 143, 111924. [CrossRef]

19. Zhang, S.; Chen, Y.; He, X.; Du, J.; Zhang, R.; Ma, Y.; Hu, X.; Zhang, Z.; Chen, Q.; Wan, X. Identification of MYB Transcription Factors Regulating Theanine Biosynthesis in Tea Plant Using Omics-Based Gene Coexpression Analysis. J. Agric. Food Chem. 2020, 68, 918-926. [CrossRef] [PubMed]

20. Century, K.S.; Reuber, T.L.; Jakob, K.; Ratcliffe, O.J. Selection of transcription factor variants. US Patents 2008/0301836A1, 4 December 2008.

21. Lipsick, J.S. One billion years of Myb. Oncogene 1996, 13, 223-235.

22. Ambawat, S.; Sharma, P.; Yadav, N.R.; Yadav, R.C. MYB transcription factor genes as regulators for plant responses: An overview. Physiol. Mol. Biol. Plants 2013, 19, 307-321. [CrossRef] [PubMed]

23. Ogata, K.; Kanei-Ishii, C.; Sasaki, M.; Hatanaka, H.; Nagadoi, A.; Enari, M.; Nakamura, H.; Nishimura, Y.; Ishii, S.; Sarai, A. The cavity in the hydrophobic core of Myb DNA-binding domain is reserved for DNA recognition and trans-activation. Nat. Genet. 1996, 3, 178-187. [CrossRef]

24. Dubos, C.; Stracke, R.; Grotewold, E.; Weisshaar, B.; Martin, C.; Lepiniec, L. MYB transcription factors in Arabidopsis. Trends Plant Sci. 2010, 15, 573-581. [CrossRef]

25. Wilkins, O.; Nahal, H.; Foong, J.; Provart, N.J.; Campbell, M.M. Expansion and Diversification of the Populus R2R3-MYB Family of Transcription Factors. Plant Physiol. 2008, 149, 981-993. [CrossRef]

26. Jin, H.; Martin, C. Multifunctionality and diversity within the plant MYB-gene family. Plant Mol. Biol. 1999, 41, 577-585. [CrossRef] [PubMed]

27. Du, H.; Zhang, L.; Liu, L.; Tang, X.-F.; Yang, W.-J.; Wu, Y.-M.; Huang, Y.-B.; Tang, Y.-X. Biochemical and molecular characterization of plant MYB transcription factor family. Biochemistry (Moscow) 2009, 74, 1-11. [CrossRef]

28. Rosinski, J.A.; Atchley, W.R. Molecular Evolution of the Myb Family of Transcription Factors: Evidence for Polyphyletic Origin. J. Mol. Evol. 1998, 46, 74-83. [CrossRef] 
29. Jiang, C.; Gu, X.; Peterson, T. Identification of conserved gene structures and carboxy-terminal motifs in the Myb gene family of Arabidopsis and Oryza sativa L. ssp. indica. Genome Biol. 2004, 5, R46. [CrossRef] [PubMed]

30. Yuan, Y.; Yang, X.; Feng, M.; Ding, H.; Khan, M.T.; Zhang, J.; Zhang, M. Genome-wide analysis of R2R3-MYB transcription factors family in the autopolyploid Saccharum spontaneum: An exploration of dominance expression and stress response. BMC Genom. 2021, 22, 622. [CrossRef]

31. Yanhui, C.; Xiaoyuan, Y.; Kun, H.; Meihua, L.; Jigang, L.; Zhaofeng, G.; Zhiqiang, L.; Yunfei, Z.; Xiaoxiao, W.; Xiaoming, Q.; et al . The MYB Transcription Factor Superfamily of Arabidopsis: Expression Analysis and Phylogenetic Comparison with the Rice MYB Family. Plant Mol. Biol. 2006, 60, 107-124. [CrossRef] [PubMed]

32. Li, X.; Guo, C.; Ahmad, S.; Wang, Q.; Yu, J.; Liu, C.; Guo, Y. Systematic Analysis of MYB Family Genes in Potato and Their Multiple Roles in Development and Stress Responses. Biomolecules 2019, 9, 317. [CrossRef] [PubMed]

33. Yang, X.; Zhou, T.; Wang, M.; Li, T.; Wang, G.; Fu, F.-F.; Cao, F. Systematic investigation and expression profiles of the GbR2R3-MYB transcription factor family in ginkgo (Ginkgo biloba L.). Int. J. Biol. Macromol. 2021, 172, 250-262. [CrossRef] [PubMed]

34. Du, H.; Feng, B.-R.; Yang, S.-S.; Huang, Y.-B.; Tang, Y.-X. The R2R3-MYB Transcription Factor Gene Family in Maize. PLoS ONE 2012, 7, e37463. [CrossRef] [PubMed]

35. Pradhan, S.; Shyamli, P.S.; Suranjika, S.; Parida, A. Genome Wide Identification and Analysis of the R2R3-MYB Transcription Factor Gene Family in the Mangrove Avicennia marina. Agronomy 2021, 11, 123. [CrossRef]

36. Liu, H.; Zhang, G.; Lv, Z.; Diao, S.; He, C.; Zhang, J. Genome-wide organization and expression profiling of the R2R3-MYB transcription factor family in sea buckthorn (Hippophae rhamnoides L.). Res. Sq. 2020, 18, 501. [CrossRef]

37. Li, Y.; Lin-Wang, K.; Liu, Z.; Allan, A.C.; Qin, S.; Zhang, J.; Liu, Y. Genome-wide analysis and expression profiles of the StR2R3-MYB transcription factor superfamily in potato (Solanum tuberosum L.). Int. J. Biol. Macromol. 2020, 148, 817-832. [CrossRef]

38. Tombuloglu, H. Genome-wide identification and expression analysis of R2R3, 3R-and 4R-MYB transcription factors during lignin biosynthesis in flax (Linum usitatissimum). Genomics 2019, 112, 782-795. [CrossRef]

39. Du, H.; Yang, S.-S.; Liang, Z.; Feng, B.-R.; Liu, L.; Huang, Y.-B.; Tang, Y.-X. Genome-wide analysis of the MYB transcription factor superfamily in soybean. BMC Plant Biol. 2012, 12, 106. [CrossRef]

40. Tan, L.; Ijaz, U.; Salih, H.; Cheng, Z.; Htet, N.N.W.; Ge, Y.; Azeem, F. Genome-Wide Identification and Comparative Analysis of MYB Transcription Factor Family in Musa acuminata and Musa balbisiana. Plants 2020, 9, 413. [CrossRef]

41. An, J.P.; Wang, X.F.; Zhang, X.W.; Xu, H.F.; Bi, S.Q.; You, C.X.; Hao, Y.J. An apple MYB transcription factor regulates cold tolerance and anthocyanin accumulation and undergoes MIEL1-mediated degradation. Plant Biotechnol. J. 2020, 18, 337-353. [CrossRef]

42. Yu, M.; Man, Y.; Wang, Y. Light- and Temperature-Induced Expression of an R2R3-MYB Gene Regulates Anthocyanin Biosynthesis in Red-Fleshed Kiwifruit. Int. J. Mol. Sci. 2019, 20, 5228. [CrossRef]

43. Hao, L.; Shi, S.; Guo, H.; Zhang, J.; Li, P.; Feng, Y. Transcriptome analysis reveals differentially expressed MYB transcription factors associated with silicon response in wheat. Sci. Rep. 2021, 11, 1-9. [CrossRef]

44. Tak, H.; Negi, S.; Ganapathi, T.R. Overexpression of MusaMYB31, a R2R3 type MYB transcription factor gene indicate its role as a negative regulator of lignin biosynthesis in banana. PLoS ONE 2017, 12, e0172695. [CrossRef]

45. Ma, D.; Constabel, C.P. MYB Repressors as Regulators of Phenylpropanoid Metabolism in Plants. Trends Plant Sci. 2019, 24, 275-289. [CrossRef]

46. Davis, G.V.; Glover, B. Characterisation of the R2R3 Myb subgroup 9 family of transcription factors in tomato. bioRxiv 2021. [CrossRef]

47. Abbas, F.; Ke, Y.; Zhou, Y.; Yu, Y.; Waseem, M.; Ashraf, U.; Wang, C.; Wang, X.; Li, X.; Yue, Y.; et al. Genome-Wide Analysis Reveals the Potential Role of MYB Transcription Factors in Floral Scent Formation in Hedychium coronarium. Front. Plant Sci. 2021, 12. [CrossRef] [PubMed]

48. Lau, S.-E.; Schwarzacher, T.; Othman, R.Y.; Harikrishna, J.A. dsRNA silencing of an R2R3-MYB transcription factor affects flower cell shape in a Dendrobium hybrid. BMC Plant Biol. 2015, 15, 1-14. [CrossRef] [PubMed]

49. Koter, M.; Święcicka, M.; Matuszkiewicz, M.; Pacak, A.; Derebecka, N.; Filipecki, M. The miRNAome dynamics during developmental and metabolic reprogramming of tomato root infected with potato cyst nematode. Plant Sci. 2018, 268, 18-29. [CrossRef] [PubMed]

50. Ballester, A.-R.; Norelli, J.; Burchard, E.; Abdelfattah, A.; Levin, E.; González-Candelas, L.; Droby, S.; Wisniewski, M. Transcriptomic Response of Resistant (PI613981-Malus sieversii) and Susceptible ("Royal Gala") Genotypes of Apple to Blue Mold (Penicillium expansum) Infection. Front. Plant Sci. 2017, 8, 1981. [CrossRef]

51. Zhou, H.; Lin-Wang, K.; Wang, F.; Espley, R.V.; Ren, F.; Zhao, J.; Ogutu, C.; He, H.; Jiang, Q.; Allan, A.C.; et al. Activator-type R2R3-MYB genes induce a repressor-type R2R3-MYB gene to balance anthocyanin and proanthocyanidin accumulation. New Phytol. 2019, 221, 1919-1934. [CrossRef]

52. Yu, Y.; Guo, D.-L.; Li, G.; Yang, Y.; Zhang, G.; Li, S.; Liang, Z. The grapevine R2R3-type MYB transcription factor VdMYB1 positively regulates defense responses by activating the stilbene synthase gene 2 (VdSTS2). BMC Plant Biol. 2019, 19, 1-15. [CrossRef]

53. Zhuang, H.; Chong, S.-L.; Borah, P.; Han, X.; Lin, E.; Tong, Z.; Huang, H. Full-Length Transcriptomic Identification of R2R3-MYB Family Genes Related to Secondary Cell Wall Development in Cunninghamia Lanceolata (Chinese Fir). Res. Sq. 2021. [CrossRef] 
54. Li, J.; Zhao, S.; Yu, X.; Du, W.; Li, H.; Sun, Y.; Sun, H.; Ruan, C. Role of Xanthoceras sorbifolium MYB44 in tolerance to combined drought and heat stress via modulation of stomatal closure and ROS homeostasis. Plant Physiol. Biochem. 2021, 162, 410-420. [CrossRef]

55. Guo, H.; Wang, Y.; Wang, L.; Hu, P.; Wang, Y.; Jia, Y.; Zhang, C.; Zhang, Y.; Zhang, Y.; Wang, C.; et al. Expression of the MYB transcription factor geneBplMYB46affects abiotic stress tolerance and secondary cell wall deposition inBetula platyphylla. Plant Biotechnol. J. 2016, 15, 107-121. [CrossRef]

56. Xiao, S.; Hu, Q.; Shen, J.; Liu, S.; Yang, Z.; Chen, K.; Klosterman, S.J.; Javornik, B.; Zhang, X.; Zhu, L. GhMYB4 downregulates lignin biosynthesis and enhances cotton resistance to Verticillium dahliae. Plant Cell Rep. 2021, 40, 735-751. [CrossRef]

57. Ullah, A.; Qamar, M.T.U.; Nisar, M.; Hazrat, A.; Rahim, G.; Khan, A.H.; Hayat, K.; Ahmed, S.; Ali, W.; Khan, A.; et al. Characterization of a novel cotton MYB gene, GhMYB108-like responsive to abiotic stresses. Mol. Biol. Rep. 2020, 47, 1573-1581. [CrossRef]

58. Shingote, P.R.; Kawar, P.G.; Pagariya, M.C.; Muley, A.B.; Babu, K.H. Isolation and functional validation of stress tolerant EaMYB18 gene and its comparative physio-biochemical analysis with transgenic tobacco plants overexpressing SoMYB18 and SsMYB18. 3 Biotech 2020, 10, 1-13. [CrossRef]

59. Bian, S.; Jin, D.; Sun, G.; Shan, B.; Zhou, H.; Wang, J.; Zhai, L.; Li, X. Characterization of the soybean R2R3-MYB transcription factor GmMYB81 and its functional roles under abiotic stresses. Gene 2020, 753, 144803. [CrossRef] [PubMed]

60. Tiwari, P.; Indoliya, Y.; Chauhan, A.S.; Singh, P.; Singh, P.K.; Singh, P.C.; Srivastava, S.; Pande, V.; Chakrabarty, D. Auxin-salicylic acid cross-talk ameliorates OsMYB-R1 mediated defense towards heavy metal, drought and fungal stress. J. Hazard. Mater. 2020, 399, 122811. [CrossRef] [PubMed]

61. He, J.; Liu, Y.; Yuan, D.; Duan, M.; Liu, Y.; Shen, Z.; Yang, C.; Qiu, Z.; Liu, D.; Wen, P.; et al. An R2R3 MYB transcription factor confers brown planthopper resistance by regulating the phenylalanine ammonia-lyase pathway in rice. Proc. Natl. Acad. Sci. USA 2019, 117, 271-277. [CrossRef] [PubMed]

62. Coleto, I.; Bejarano, I.; Marín-Peña, A.J.; Medina, J.; Rioja, C.; Burow, M.; Marino, D. Arabidopsis thaliana transcription factors MYB28 and MYB29 shape ammonium stress responses by regulating Fe homeostasis. New Phytol. 2021, 229, 1021-1035. [CrossRef]

63. Shukla, V.; Han, J.-P.; Cléard, F.; Legendre-Lefebvre, L.; Gully, K.; Flis, P.; Berhin, A.; Andersen, T.G.; Salt, D.E.; Nawrath, C.; et al. Suberin plasticity to developmental and exogenous cues is regulated by a set of MYB transcription factors. bioRxiv 2021. [CrossRef]

64. Yuan, Y.; Xu, X.; Luo, Y.; Gong, Z.; Hu, X.; Wu, M.; Liu, Y.; Yan, F.; Zhang, X.; Zhang, W.; et al. R2R3 MYB-dependent auxin signalling regulates trichome formation, and increased trichome density confers spider mite tolerance on tomato. Plant Biotechnol. J. 2020, 19, 138-152. [CrossRef] [PubMed]

65. Li, G.; Quan, R.; Jing, P.; Wang, M.; Xu, W.; Hu, H. Cloning, Subcellular Location and Expression Analysis of Grape MYB Gene. Res. Sq. 2021. [CrossRef]

66. Carey, C.C.; Strahle, J.T.; Selinger, D.A.; Chandler, V.L. Mutations in the pale aleurone color1 Regulatory Gene of the Zea mays Anthocyanin Pathway Have Distinct Phenotypes Relative to the Functionally Similar TRANSPARENT TESTA GLABRA1 Gene in Arabidopsis thaliana. Plant Cell 2004, 16, 450-464. [CrossRef] [PubMed]

67. Baudry, A.; Heim, M.A.; Dubreucq, B.; Caboche, M.; Weisshaar, B.; Lepiniec, L. TT2, TT8, and TTG1 synergistically specify the expression of BANYULS and proanthocyanidin biosynthesis in Arabidopsis thaliana. Plant J. Cell Mol. Biol. 2004, 39, 366-380. [CrossRef]

68. Feller, A.; Machemer, K.; Braun, E.; Grotewold, E. Evolutionary and comparative analysis of MYB and bHLH plant transcription factors. Plant J. 2011, 66, 94-116. [CrossRef] [PubMed]

69. Kasajima, I.; Sasaki, K. A chimeric repressor of petunia PH4 R2R3-MYB family transcription factor generates margined flowers in torenia. Plant Signal. Behav. 2016, 11, e1177693. [CrossRef] [PubMed]

70. Hichri, I.; Barrieu, F.; Bogs, J.; Kappel, C.; Delrot, S.; Lauvergeat, V. Recent advances in the transcriptional regulation of the flavonoid biosynthetic pathway. J. Exp. Bot. 2011, 62, 2465-2483. [CrossRef] [PubMed]

71. Chen, L.; Hu, B.; Qin, Y.; Hu, G.; Zhao, J. Advance of the negative regulation of anthocyanin biosynthesis by MYB transcription factors. Plant Physiol. Biochem. 2019, 136, 178-187. [CrossRef]

72. Saigo, T.; Wang, T.; Watanabe, M.; Tohge, T. Diversity of anthocyanin and proanthocyanin biosynthesis in land plants. Curr. Opin. Plant Biol. 2020, 55, 93-99. [CrossRef] [PubMed]

73. Tohge, T.; Fernie, A.R. Leveraging Natural Variance towards Enhanced Understanding of Phytochemical Sunscreens. Trends Plant Sci. 2017, 22, 308-315. [CrossRef] [PubMed]

74. Butelli, E.; Titta, L.; Giorgio, M.; Mock, H.-P.; Matros, A.; Peterek, S.; Schijlen, E.G.W.M.; Hall, R.; Bovy, A.G.; Luo, J.; et al. Enrichment of tomato fruit with health-promoting anthocyanins by expression of select transcription factors. Nat. Biotechnol. 2008, 26, 1301-1308. [CrossRef]

75. Sakai, M.; Yamagishi, M.; Matsuyama, K. Repression of anthocyanin biosynthesis by R3-MYB transcription factors in lily (Lilium spp.). Plant Cell Rep. 2019, 38, 609-622. [CrossRef] [PubMed]

76. Person, A.E.; Cooley, A. Petal Anthocyanin Evolution by R2R3 MYBs in Mimulus Cupreus and Mimulus Luteus var. Variegatus. 2019. Available online: https://arminda.whitman.edu/islandora/object/arminda\%3A62223/datastream/PDF/view (accessed on 24 August 2021). 
77. Li, C.; Qiu, J.; Yang, G.; Huang, S.; Yin, J. Ectopic expression of the Anthurium andraeanum (Hort.) R2R3-MYB genes AaMYB4 and AaMYB5 enhance the flower color in transgenic tobacco. Plant Cell, Tissue Organ Cult. (PCTOC) 2019, 139, 105-117. [CrossRef]

78. Nakatsuka, T.; Suzuki, T.; Harada, K.; Kobayashi, Y.; Dohra, H.; Ohno, H. Floral organ- and temperature-dependent regulation of anthocyanin biosynthesis in Cymbidium hybrid flowers. Plant Sci. 2019, 287, 110173. [CrossRef] [PubMed]

79. Yan, S.; Chen, N.; Huang, Z.; Li, D.; Zhi, J.; Yu, B.; Liu, X.; Cao, B.; Qiu, Z. Anthocyanin Fruit encodes an R2R3-MYB transcription factor, SlAN2-like, activating the transcription of SIMYBATV to fine-tune anthocyanin content in tomato fruit. New Phytol. 2020, 225, 2048-2063. [CrossRef]

80. Liu, Y.; Ma, K.; Qi, Y.; Lv, G.; Ren, X.; Liu, Z.; Ma, F. Transcriptional Regulation of Anthocyanin Synthesis by MYB-bHLH-WDR Complexes in Kiwifruit (Actinidia chinensis). J. Agric. Food Chem. 2021, 69, 3677-3691. [CrossRef]

81. Dixon, R.A.; Xie, D.Y.; Sharma, S.B. Proanthocyanidins-a final frontier in flavonoid research? New Phytol. 2005, 165, 9-28. [CrossRef]

82. Gil-Muñoz, F.; Sánchez-Navarro, J.A.; Besada, C.; Salvador, A.; Badenes, M.L.; del Mar Naval, M.; Ríos, G. MBW complexes impinge on anthocyanidin reductase gene regulation for proanthocyanidin biosynthesis in persimmon fruit. Sci Rep 2020, 10, 3543. [CrossRef]

83. Rauf, A.; Imran, M.; Abu-Izneid, T.; Haq, I.U.; Patel, S.; Pan, X.; Naz, S.; Silva, A.S.; Saeed, F.; Suleria, H.A.R. Proanthocyanidins: A comprehensive review. Biomed. Pharmacother. 2019, 116, 108999. [CrossRef]

84. Malisch, C.; Lüscher, A.; Baert, N.; Engström, M.; Studer, B.; Fryganas, C.; Suter, D.; Mueller-Harvey, I.; Salminen, J.-P. Large Variability of Proanthocyanidin Content and Composition in Sainfoin (Onobrychis viciifolia). J. Agric. Food Chem. 2015, 63, 10234-10242. [CrossRef]

85. Stringano, E.; Carbonero, C.H.; Smith, L.M.; Brown, R.H.; Mueller-Harvey, I. Proanthocyanidin diversity in the EU 'HealthyHay' sainfoin (Onobrychis viciifolia) germplasm collection. Phytochemistry 2012, 77, 197-208. [CrossRef]

86. Hong, M.; Hu, K.; Tian, T.; Li, X.; Chen, L.; Zhang, Y.; Yi, B.; Wen, J.; Ma, C.; Shen, J.; et al. Transcriptomic Analysis of Seed Coats in Yellow-Seeded Brassica napus Reveals Novel Genes That Influence Proanthocyanidin Biosynthesis. Front. Plant Sci. 2017, 8, 1674. [CrossRef]

87. Wang, G.; Yang, B.; Wu, J.; Luo, P.; Anwar, M.; Allan, A.C.; Lin-Wang, K.; Espley, R.V.; Zeng, L. Identification of Genes Involved in Flavonoid Biosynthesis of Chinese Narcissus (Narcissus tazetta L. var. chinensis). Plant Mol. Biol. Rep. 2018, 36, 812-821. [CrossRef]

88. Fan, Y.; Peng, J.; Wu, J.; Zhou, P.; He, R.; Allan, A.C.; Zeng, L. NtbHLH1, a JAF13-like bHLH, interacts with NtMYB6 to enhance proanthocyanidin accumulation in Chinese Narcissus. BMC Plant Biol. 2021, 21, 1-14. [CrossRef] [PubMed]

89. Barbehenn, R.V.; Peter Constabel, C. Tannins in plant-herbivore interactions. Phytochemistry 2011, 72, 1551-1565. [CrossRef]

90. Barbehenn, R.V.; Jones, C.P.; Karonen, M.; Salminen, J.-P. Tannin Composition Affects the Oxidative Activities of Tree Leaves. J. Chem. Ecol. 2006, 32, 2235-2251. [CrossRef]

91. Min, B.; Barry, T.; Attwood, G.; McNabb, W. The effect of condensed tannins on the nutrition and health of ruminants fed fresh temperate forages: A review. Anim. Feed. Sci. Technol. 2003, 106, 3-19. [CrossRef]

92. Li, Y.; Shan, X.; Zhou, L.; Gao, R.; Yang, S.; Wang, S.; Wang, L.; Gao, X. The R2R3-MYB Factor FhMYB5 From Freesia hybrida Contributes to the Regulation of Anthocyanin and Proanthocyanidin Biosynthesis. Front. Plant Sci. 2019, 9, 1935. [CrossRef] [PubMed]

93. Novobilský, A.; Stringano, E.; Carbonero, C.H.; Smith, L.; Enemark, H.; Mueller-Harvey, I.; Thamsborg, S.M. In vitro effects of extracts and purified tannins of sainfoin (Onobrychis viciifolia) against two cattle nematodes. Vet. Parasitol. 2013, 196, 532-537. [CrossRef]

94. Miranda, M.; Ralph, S.G.; Mellway, R.; White, R.; Heath, M.C.; Bohlmann, J.; Constabel, C.P. The Transcriptional Response of Hybrid Poplar (Populus trichocarpa $\times$ P. deltoids) to Infection by Melampsora medusae Leaf Rust Involves Induction of Flavonoid Pathway Genes Leading to the Accumulation of Proanthocyanidins. Mol. Plant Microbe Interact. 2007, 20, 816-831. [CrossRef]

95. Kumar, V.; Sharma, A.; Kohli, S.K.; Bali, S.; Sharma, M.; Kumar, R.; Bhardwaj, R.; Thukral, A.K. Differential distribution of polyphenols in plants using multivariate techniques. Biotechnol. Res. Innov. 2019, 3, 1-21. [CrossRef]

96. Tanase, C.; Bujor, O.-C.; Popa, V.I. Phenolic Natural Compounds and Their Influence on Physiological Processes in Plants. In Polyphenols in Plants, 2nd ed.; Academic Press: Cambridge, MA, USA, 2018; pp. 45-58. [CrossRef]

97. Mattila, P.; Hellström, J. Phenolic acids in potatoes, vegetables, and some of their products. J. Food Compos. Anal. 2007, 20, 152-160. [CrossRef]

98. Sharma, A.; Shahzad, B.; Rehman, A.; Bhardwaj, R.; Landi, M.; Zheng, B. Response of Phenylpropanoid Pathway and the Role of Polyphenols in Plants under Abiotic Stress. Molecules 2019, 24, 2452. [CrossRef]

99. Ding, K.; Pei, T.; Bai, Z.; Jia, Y.; Ma, P.; Liang, Z. SmMYB36, a Novel R2R3-MYB Transcription Factor, Enhances Tanshinone Accumulation and Decreases Phenolic Acid Content in Salvia miltiorrhiza Hairy Roots. Sci. Rep. 2017, 7, 1-15. [CrossRef]

100. Deng, C.; Wang, Y.; Huang, F.; Lu, S.; Zhao, L.; Ma, X.; Kai, G. SmMYB2 promotes salvianolic acid biosynthesis in the medicinal herb Salvia miltiorrhiza. J. Integr. Plant Biol. 2020, 62, 1688-1702. [CrossRef]

101. Zhou, W.; Shi, M.; Deng, C.; Lu, S.; Huang, F.; Wang, Y.; Kai, G. The methyl jasmonate-responsive transcription factor SmMYB1 promotes phenolic acid biosynthesis in Salvia miltiorrhiza. Hortic. Res. 2021, 8, 1-13. [CrossRef]

102. Li, X.; Gao, M.J.; Pan, H.Y.; Cui, D.J.; Gruber, M.Y. Purple canola: Arabidopsis PAP1 increases antioxidants and phenolics in Brassica napus leaves. J. Agric. Food Chem. 2010, 58, 1639-1645. [CrossRef] 
103. Dias, A.P.; Grotewold, E. Manipulating the accumulation of phenolics in maize cultured cells using transcription factors. Biochem. Eng. J. 2003, 14, 207-216. [CrossRef]

104. Jin, H.; Cominelli, E.; Bailey, P.; Parr, A.; Mehrtens, F.; Jones, J.; Tonelli, C.; Weisshaar, B.; Martin, C. Transcriptional repression by AtMYB4 controls production of UV-protecting sunscreens in Arabidopsis. EMBO J. 2000, 19, 6150-6161. [CrossRef]

105. Zhang, Y.; Yan, Y.-P.; Wang, Z.-Z. TheArabidopsis PAP1Transcription Factor Plays an Important Role in the Enrichment of Phenolic Acids inSalvia miltiorrhiza. J. Agric. Food Chem. 2010, 58, 12168-12175. [CrossRef]

106. Wang, D.; Song, Y.; Chen, Y.; Yao, W.; Li, Z.; Liu, W.; Yue, S.; Wang, Z. Metabolic pools of phenolic acids in Salvia miltiorrhiza are enhanced by co-expression of Antirrhinum majus Delila and Rosea1 transcription factors. Biochem. Eng. J. 2013, 74, 115-120. [CrossRef]

107. Zhang, S.; Ma, P.; Yang, D.; Li, W.; Liang, Z.; Liu, Y.; Liu, F. Cloning and Characterization of a Putative R2R3 MYB Transcriptional Repressor of the Rosmarinic Acid Biosynthetic Pathway from Salvia miltiorrhiza. PLoS ONE 2013, 8, e73259. [CrossRef]

108. Kai, G.; Xu, H.; Zhou, C.; Liao, P.; Xiao, J.; Luo, X.; You, L.; Zhang, L. Metabolic engineering tanshinone biosynthetic pathway in Salvia miltiorrhiza hairy root cultures. Metab. Eng. 2011, 13, 319-327. [CrossRef]

109. Zhou, W.; Huang, F.; Li, S.; Wang, Y.; Zhou, C.; Shi, M.; Wang, J.; Chen, Y.; Wang, Y.; Wang, H.; et al. Molecular cloning and characterization of two 1-deoxy-d-xylulose-5-phosphate synthase genes involved in tanshinone biosynthesis in Salvia miltiorrhiza. Mol. Breed. 2016, 36, 124. [CrossRef]

110. Hao, X.; Pu, Z.; Cao, G.; You, D.; Zhou, Y.; Deng, C.; Shi, M.; Nile, S.H.; Wang, Y.; Zhou, W.; et al. Tanshinone and salvianolic acid biosynthesis are regulated by SmMYB98 in Salvia miltiorrhiza hairy roots. J. Adv. Res. 2020, 23, 1-12. [CrossRef]

111. Liu, L.; Yang, D.; Xing, B.; Zhang, C.; Liang, Z. SmMYB98b positive regulation to tanshinones in Salvia miltiorrhiza Bunge hairy roots. Plant Cell Tissue Organ Cult. (PCTOC) 2019, 140, 459-467. [CrossRef]

112. Zhang, J.; Zhou, L.; Zheng, X.; Zhang, J.; Yang, L.; Tan, R.; Zhao, S. Overexpression of SmMYB9b enhances tanshinone concentration in Salvia miltiorrhiza hairy roots. Plant Cell Rep. 2017, 36, 1297-1309. [CrossRef]

113. Stracke, R.; Ishihara, H.; Huep, G.; Barsch, A.; Mehrtens, F.; Niehaus, K.; Weisshaar, B. Differential regulation of closely related R2R3-MYB transcription factors controls flavonol accumulation in different parts of the Arabidopsis thaliana seedling. Plant $J$. 2007, 50, 660-677. [CrossRef] [PubMed]

114. Kuhn, B.M.; Geisler, M.; Bigler, L.; Ringli, C. Flavonols accumulate asymmetrically and affect auxin transport in Arabidopsis. Plant Physiol. 2011, 156, 585-595. [CrossRef]

115. Forbes, A.M.; Meier, G.P.; Haendiges, S.; Taylor, L.P. Structure-Activity Relationship Studies of Flavonol Analogues on Pollen Germination. J. Agric. Food Chem. 2014, 62, 2175-2181. [CrossRef] [PubMed]

116. Blanco, E.; Sabetta, W.; Danzi, D.; Negro, D.; Passeri, V.; De Lisi, A.; Paolocci, F.; Sonnante, G. Isolation and Characterization of the Flavonol Regulator CcMYB12 From the Globe Artichoke [Cynara cardunculus var. scolymus (L.) Fiori]. Front. Plant Sci. 2018, 9, 941. [CrossRef] [PubMed]

117. Naik, J.; Rajput, R.; Pucker, B.; Stracke, R.; Pandey, A. The R2R3-MYB transcription factor MtMYB134 orchestrates flavonol biosynthesis in Medicago truncatula. Plant Mol. Biol. 2021, 106, 157-172. [CrossRef] [PubMed]

118. Nakatsuka, T.; Saito, M.; Yamada, E.; Fujita, K.; Kakizaki, Y.; Nishihara, M. Isolation and characterization of GtMYBP3 and GtMYBP4, orthologues of R2R3-MYB transcription factors that regulate early flavonoid biosynthesis, in gentian flowers. J. Exp. Bot. 2012, 63, 6505-6517. [CrossRef]

119. Czemmel, S.; Stracke, R.; Weisshaar, B.; Cordon, N.; Harris, N.N.; Walker, A.; Robinson, S.; Bogs, J. The Grapevine R2R3-MYB Transcription Factor VvMYBF1 Regulates Flavonol Synthesis in Developing Grape Berries. Plant Physiol. 2009, 151, 1513-1530. [CrossRef]

120. Deluc, L.; Barrieu, F.; Marchive, C.; Lauvergeat, V.; Decendit, A.; Richard, T.; Carde, J.-P.; Mérillon, J.-M.; Hamdi, S. Characterization of a Grapevine R2R3-MYB Transcription Factor That Regulates the Phenylpropanoid Pathway. Plant Physiol. 2005, 140, 499-511. [CrossRef]

121. Rommens, C.M.; Richael, C.M.; Yan, H.; Navarre, D.A.; Ye, J.; Krucker, M.; Swords, K. Engineered native pathways for high kaempferol and caffeoylquinate production in potato. Plant Biotechnol. J. 2008, 6, 870-886. [CrossRef]

122. Gates, D.J.; Olson, B.; Clemente, T.E.; Smith, S.D. A novel R3 MYB transcriptional repressor associated with the loss of floral pigmentation in Iochroma. New Phytol. 2018, 217, 1346-1356. [CrossRef]

123. Xu, F.; Ning, Y.; Zhang, W.; Liao, Y.; Li, L.; Cheng, H.; Cheng, S. An R2R3-MYB transcription factor as a negative regulator of the flavonoid biosynthesis pathway in Ginkgo biloba. Funct. Integr. Genom. 2013, 14, 177-189. [CrossRef]

124. Yan, J.; Wang, B.; Zhong, Y.; Yao, L.; Cheng, L.; Wu, T. The soybean R2R3 MYB transcription factor GmMYB100 negatively regulates plant flavonoid biosynthesis. Plant Mol. Biol. 2015, 89, 35-48. [CrossRef]

125. Hu, Q.; Yang, L.; Liu, S.; Zhou, L.; Wang, X.; Wang, W.; Cai, L.; Wu, X.; Chang, Y.; Wang, S. A repressor motif-containing poplar R3 MYB-like transcription factor regulates epidermal cell fate determination and anthocyanin biosynthesis in Arabidopsis. $J$. Plant Biol. 2016, 59, 525-535. [CrossRef]

126. Lin, S.; Singh, R.K.; Moehninsi; Navarre, D.A. R2R3-MYB transcription factors, StmiR858 and sucrose mediate potato flavonol biosynthesis. Hortic. Res. 2021, 8, 1-13. [CrossRef]

127. Wang, X.-C.; Wu, J.; Guan, M.; Zhao, C.; Geng, P.; Zhao, Q. Arabidopsis MYB4 plays dual roles in flavonoid biosynthesis. Plant J. 2019, 101, 637-652. [CrossRef] 
128. Li, L.; He, Y.; Ge, H.; Liu, Y.; Chen, H. Functional characterization of SmMYB86, a negative regulator of anthocyanin biosynthesis in eggplant (Solanum melongena L.). Plant Sci. 2020, 302, 110696. [CrossRef]

129. Gomez-Gomez, L.; Trapero-Mozos, A.; Gomez; Rubio-Moraga, A.; Ahrazem, O. Identification and possible role of a MYB transcription factor from saffron (Crocus sativus). J. Plant Physiol. 2012, 169, 509-515. [CrossRef]

130. Mitsuda, N.; Hiratsu, K.; Todaka, D.; Nakashima, K.; Yamaguchi-Shinozaki, K.; Ohme-Takagi, M. Efficient production of male and female sterile plants by expression of a chimeric repressor in Arabidopsis and rice. Plant Biotechnol. J. 2006, 4, 325-332. [CrossRef]

131. Higginson, T.; Li, S.F.; Parish, R.W. AtMYB103regulates tapetum and trichome development in Arabidopsis thaliana. Plant J. 2003, 35, 177-192. [CrossRef]

132. Wan, S.; Li, C.; Ma, X.; Luo, K. PtrMYB57 contributes to the negative regulation of anthocyanin and proanthocyanidin biosynthesis in poplar. Plant Cell Rep. 2017, 36, 1263-1276. [CrossRef]

133. Preston, J.; Wheeler, J.; Heazlewood, J.; Li, S.F.; Parish, R.W. AtMYB32 is required for normal pollen development in Arabidopsis thaliana. Plant J. 2004, 40, 979-995. [CrossRef]

134. Chen, S.; Peng, S.; Huang, G.; Wu, K.; Fu, X.; Chen, Z. Association of decreased expression of a Myb transcription factor with the TPD (tapping panel dryness) syndrome in Hevea brasiliensis. Plant Mol. Biol. 2003, 51, 51-58. [CrossRef]

135. Kranz, H.D.; Denekamp, M.; Greco, R.; Jin, H.; Leyva, A.; Meissner, R.C.; Petroni, K.; Urzainqui, A.; Bevan, M.; Martin, C.; et al. Towards functional characterisation of the members of the R2R3-MYB gene family from Arabidopsis thaliana. Plant J. Cell Mol. Biol. 1998, 16, 263-276. [CrossRef]

136. De Vos, M.; Denekamp, M.; Dicke, M.; Vuylsteke, M.; Van Loon, L.; Smeekens, S.C.; Pieterse, C.M. TheArabidopsis thalianaTranscription Factor AtMYB102 Functions in Defense Against The Insect HerbivorePieris rapae. Plant Signal. Behav. 2006, 1, 305-311. [CrossRef]

137. Hsu, C.-Y.; Jenkins, J.N.; Saha, S.; Ma, D.-P. Transcriptional regulation of the lipid transfer protein gene LTP3 in cotton fibers by a novel MYB protein. Plant Sci. 2005, 168, 167-181. [CrossRef]

138. Woodger, F.J.; Gubler, F.; Pogson, B.; Jacobsen, J.V. A Mak-like kinase is a repressor of GAMYB in barley aleurone. Plant J. 2003, 33, 707-717. [CrossRef]

139. Du, H.; Tang, X.-F.; Liu, L.; Yang, W.-J.; Wu, Y.-M.; Huang, Y.-B.; Tang, Y.-X. Cloning and functional identification of two MYB transcription factors GmMYBJ6 and GmMYBJ7 in soybean. Acta Agron. Sin. 2008, 34, 1179-1187. [CrossRef]

140. Chen, C.; Zhang, K.; Khurshid, M.; Li, J.; He, M.; Georgiev, M.; Zhang, X.; Zhou, M. MYB Transcription Repressors Regulate Plant Secondary Metabolism. Crit. Rev. Plant Sci. 2019, 38, 159-170. [CrossRef]

141. Gao, J.-J.; Shen, X.-F.; Zhang, Z.; Peng, R.-H.; Xiong, A.-S.; Xu, J.; Zhu, B.; Zheng, J.-L.; Yao, Q.-H. The myb transcription factor MdMYB6 suppresses anthocyanin biosynthesis in transgenic Arabidopsis. Plant Cell, Tissue Organ Cult. (PCTOC) 2011, 106, 235-242. [CrossRef]

142. Salvatierra, A.; Pimentel, P.; Moya-León, M.A.; Herrera, R. Increased accumulation of anthocyanins in Fragaria chiloensis fruits by transient suppression of FcMYB1 gene. Phytochemistry 2013, 90, 25-36. [CrossRef]

143. Xu, H.; Yang, G.; Zhang, J.; Wang, Y.; Zhang, T.; Wang, N.; Jiang, S.; Zhang, Z.; Chen, X. Overexpression of a repressor MdMYB15L negatively regulates anthocyanin and cold tolerance in red-fleshed callus. Biochem. Biophys. Res. Commun. 2018, 500, 405-410. [CrossRef]

144. Tamagnone, L.; Merida, A.; Parr, A.; Mackay, S.; Culianez-Macia, F.A.; Roberts, K.; Martin, C. The AmMYB308 and AmMYB330 transcription factors from antirrhinum regulate phenylpropanoid and lignin biosynthesis in transgenic tobacco. Plant Cell 1998, 10, 135-154. [CrossRef]

145. Song, L.; Wang, X.; Han, W.; Qu, Y.; Wang, Z.; Zhai, R.; Yang, C.; Ma, F.; Xu, L. PbMYB120 Negatively Regulates Anthocyanin Accumulation in Pear. Int. J. Mol. Sci. 2020, 21, 1528. [CrossRef] [PubMed]

146. Zhou, M.; Zhang, K.; Sun, Z.; Yan, M.; Chen, C.; Zhang, X.; Tang, Y.; Wu, Y. LNK1 and LNK2 Corepressors Interact with the MYB3 Transcription Factor in Phenylpropanoid Biosynthesis. Plant Physiol. 2017, 174, 1348-1358. [CrossRef]

147. Aharoni, A.; De Vos, C.H.R.; Wein, M.; Sun, Z.; Greco, R.; Kroon, A.; Mol, J.N.M.; O'Connell, A.P. The strawberry FaMYB1 transcription factor suppresses anthocyanin and flavonol accumulation in transgenic tobacco. Plant J. 2001, 28, 319-332. [CrossRef]

148. Shi, X. Regulatory Functions of ZmMYB31 and ZmMYB42 in Maize Phenylpropanoid Pathway. Ph.D. Thesis, University of Toledo, Toledo, OH, USA, 2011.

149. Park, J.-S.; Kim, J.-B.; Cho, K.-J.; Cheon, C.-I.; Sung, M.-K.; Choung, M.-G.; Roh, K.-H. Arabidopsis R2R3-MYB transcription factor AtMYB60 functions as a transcriptional repressor of anthocyanin biosynthesis in lettuce (Lactuca sativa). Plant Cell Rep. 2008, 27, 985-994. [CrossRef]

150. Huang, Y.-F.; Vialet, S.; Guiraud, J.; Torregrosa, L.; Bertrand, Y.; Cheynier, V.; This, P.; Terrier, N. A negative MYB regulator of proanthocyanidin accumulation, identified through expression quantitative locus mapping in the grape berry. New Phytol. 2013, 201, 795-809. [CrossRef] [PubMed]

151. Carrier, G.; Huang, Y.-F.; Le Cunff, L.; Fournier-Level, A.; Vialet, S.; Souquet, J.-M.; Cheynier, V.; Terrier, N.; This, P. Selection of candidate genes for grape proanthocyanidin pathway by an integrative approach. Plant Physiol. Biochem. 2013, 72, 87-95. [CrossRef]

152. Xu, H.; Wang, N.; Liu, J.; Qu, C.; Wang, Y.; Jiang, S.; Lu, N.; Wang, D.; Zhang, Z.; Chen, X. The molecular mechanism underlying anthocyanin metabolism in apple using the MdMYB16 and MdbHLH33 genes. Plant Mol. Biol. 2017, 94, 149-165. [CrossRef] 
153. Kim, J.H.; Hyun, W.Y.; Nguyen, H.N.; Jeong, C.Y.; Xiong, L.; Hong, S.W.; Lee, H. AtMyb7, a subgroup 4 R2R3 Myb, negatively regulates ABA-induced inhibition of seed germination by blocking the expression of the bZIP transcription factor ABI5. Plant Cell Environ. 2015, 38, 559-571. [CrossRef]

154. Ma, Q.H.; Wang, C.; Zhu, H.H. TaMYB4 cloned from wheat regulates lignin biosynthesis through negatively controlling the transcripts of both cinnamyl alcohol dehydrogenase and cinnamoyl-CoA reductase genes. Biochimie 2011, 93, 1179-1186. [CrossRef]

155. Vimolmangkang, S.; Han, Y.; Wei, G.; Korban, S.S. An apple MYB transcription factor, MdMYB3, is involved in regulation of anthocyanin biosynthesis and flower development. BMC Plant Biol. 2013, 13, 176. [CrossRef] [PubMed]

156. Zhu, L.; Guan, Y.; Zhang, Z.; Song, A.; Chen, S.; Jiang, J.; Chen, F. CmMYB8 encodes an R2R3 MYB transcription factor which represses lignin and flavonoid synthesis in chrysanthemum. Plant Physiol. Biochem. 2020, 149, 217-224. [CrossRef] [PubMed]

157. Huang, D.; Tang, Z.; Fu, J.; Yuan, Y.; Deng, X.; Xu, Q. CsMYB3 and CsRuby1 form an 'Activator-and-Repressor' Loop for the Regulation of Anthocyanin Biosynthesis in Citrus. Plant Cell Physiol. 2019, 61, 318-330. [CrossRef]

158. Pérez-Díaz, J.R.; Pérez-Díaz, J.; Madrid-Espinoza, J.; González-Villanueva, E.; Moreno, Y.; Ruiz-Lara, S. New member of the R2R3-MYB transcription factors family in grapevine suppresses the anthocyanin accumulation in the flowers of transgenic tobacco. Plant Mol. Biol. 2015, 90, 63-76. [CrossRef] [PubMed]

159. Zhu, Z.; Li, G.; Liu, L.; Zhang, Q.; Han, Z.; Chen, X.; Li, B. A R2R3-MYB Transcription Factor, VvMYBC2L2, Functions as a Transcriptional Repressor of Anthocyanin Biosynthesis in Grapevine (Vitis vinifera L.). Molecules 2018, 24, 92. [CrossRef]

160. Su, X.; Xia, Y.; Jiang, W.; Shen, G.; Pang, Y. GbMYBR1 from Ginkgo biloba represses phenylpropanoid biosynthesis and trichome development in Arabidopsis. Planta 2020, 252, 1-18. [CrossRef]

161. Deng, G.-M.; Zhang, S.; Yang, Q.-S.; Gao, H.-J.; Sheng, O.; Bi, F.-C.; Li, C.-Y.; Dong, T.; Yi, G.-J.; He, W.-D.; et al. MaMYB4, an R2R3-MYB Repressor Transcription Factor, Negatively Regulates the Biosynthesis of Anthocyanin in Banana. Front. Plant Sci. 2021, 11. [CrossRef]

162. Yoshida, K.; Ma, D.; Constabel, C.P. The MYB182 Protein Down-Regulates Proanthocyanidin and Anthocyanin Biosynthesis in Poplar by Repressing Both Structural and Regulatory Flavonoid Genes. Plant Physiol. 2015, 167, 693-710. [CrossRef]

163. Fornale, S.; Lopez, E.; Salazar-Henao, J.E.; Nohales, P.F.; Rigau, J.; Caparros-Ruiz, D. AtMYB7, a New Player in the Regulation of UV-Sunscreens in Arabidopsis thaliana. Plant Cell Physiol. 2014, 55, 507-516. [CrossRef]

164. Zhu, H.-F.; Fitzsimmons, K.; Khandelwal, A.; Kranz, R.G. CPC, a Single-Repeat R3 MYB, Is a Negative Regulator of Anthocyanin Biosynthesis in Arabidopsis. Mol. Plant 2009, 2, 790-802. [CrossRef]

165. Matsui, K.; Umemura, Y.; Ohme-Takagi, M. AtMYBL2, a protein with a single MYB domain, acts as a negative regulator of anthocyanin biosynthesis in Arabidopsis. Plant J. 2008, 55, 954-967. [CrossRef]

166. Paolocci, F.; Robbins, M.P.; Passeri, V.; Hauck, B.; Morris, P.; Rubini, A.; Arcioni, S.; Damiani, F. The strawberry transcription factor FaMYB1 inhibits the biosynthesis of proanthocyanidins in Lotus corniculatus leaves. J. Exp. Bot. 2010, 62, 1189-1200. [CrossRef]

167. Albert, N.W.; Davies, K.M.; Lewis, D.H.; Zhang, H.; Montefiori, M.; Brendolise, C.; Boase, M.; Ngo, H.; Jameson, P.; Schwinn, K.E. A Conserved Network of Transcriptional Activators and Repressors Regulates Anthocyanin Pigmentation in Eudicots. Plant Cell 2014, 26, 962-980. [CrossRef]

168. Li, Y.; Shan, X.; Gao, R.; Han, T.; Zhang, J.; Wang, Y.; Kimani, S.; Wang, L.; Gao, X. MYB repressors and MBW activation complex collaborate to fine-tune flower coloration in Freesia hybrida. Commun. Biol. 2020, 3, 1-14. [CrossRef]

169. Zhu, L.; Shan, H.; Chen, S.; Jiang, J.; Gu, C.; Zhou, G.; Chen, Y.; Song, A.; Chen, F. The Heterologous Expression of the Chrysanthemum R2R3-MYB Transcription Factor CmMYB1 Alters Lignin Composition and Represses Flavonoid Synthesis in Arabidopsis thaliana. PLoS ONE 2013, 8, e65680. [CrossRef] [PubMed]

170. Zhang, H.; Gong, J.; Chen, K.; Yao, W.; Zhang, B.; Wang, J.; Tian, S.; Liu, H.; Wang, Y.; Liu, Y.; et al. A novel R3 MYB transcriptional repressor, MaMYBx, finely regulates anthocyanin biosynthesis in grape hyacinth. Plant Sci. 2020, 298, 110588. [CrossRef] [PubMed]

171. Wu, J.; Wang, G.; Anwar, M.; Zeng, L. Cloning and functional analysis of R2R3-MYB gene NtMYB5 in Narcissus tazetta var. chinensis. Acta Hortic. Sin. 2018, 45, 1327-1337.

172. Liu, R.; Lai, B.; Hu, B.; Qin, Y.; Hu, G.; Zhao, J. Identification of MicroRNAs and Their Target Genes Related to the Accumulation of Anthocyanins in Litchi chinensis by High-Throughput Sequencing and Degradome Analysis. Front. Plant Sci. 2017, 7, 758. [CrossRef]

173. Dubos, C.; Le Gourrierec, J.; Baudry, A.; Huep, G.; Lanet, E.; Debeaujon, I.; Routaboul, J.-M.; Alboresi, A.; Weisshaar, B.; Lepiniec, L. MYBL2 is a new regulator of flavonoid biosynthesis inArabidopsis thaliana. Plant J. 2008, 55, 940-953. [CrossRef]

174. Nemie-Feyissa, D.; Olafsdottir, S.M.; Heidari, B.; Lillo, C. Nitrogen depletion and small R3-MYB transcription factors affecting anthocyanin accumulation in Arabidopsis leaves. Phytochemistry 2014, 98, 34-40. [CrossRef] [PubMed] 